\title{
PRÁTICAS FUNERÁRIAS, CULTO AOS ANCESTRAIS E TRANSMISSÃO DO PATRIMÔNIO FAMILIAR NA ANTIGA MESOPOTÂMIA
}

\author{
Marcelo Rede*
}

\begin{abstract}
REDE, M. Práticas funerárias, culto aos ancestrais e transmissão do patrimônio familiar na antiga Mesopotâmia. Rev. do Museu de Arqueologia e Etnologia, São Paulo, 14: 117-138, 2004.
\end{abstract}

RESUMO: Procurou-se, neste artigo, estabelecer a relação entre dois fenômenos: por um lado, a transmissão do patrimônio familiar e, por outro, as práticas funerárias, em particular em contextos de inumações no subsolo da casa. Pode-se verificar que a necessidade de assegurar o culto dos ancestrais através dos ritos funerários teve um importante papel no processo de herança material e simbólica do grupo doméstico na região babilônica e foi decisivo para diferenciar a posição do filho primogênito daquela dos demais herdeiros.

UNITERMOS: Patrimônio - Herança - Práticas funerárias - Mesopotâmia -Larsa - Culto aos ancestrais.

Em algumas sociedades, a concepção e a prática da herança comportam um certo grau de tensão entre o atual controlador de bens e posições e os futuros detentores de tais direitos. Se esta tensão já é presente em vida, é no momento da morte que ela ganha uma nova dimensão: a passagem do chefe do grupo familiar para o mundo dos mortos, longe de pôr fim ao estado de disputa, determina sua inserção no panteão dos ancestrais e, assim fazendo, desloca as contradições para um nível simbólico e ritual. Aideologia da morte e os cultos mortuários são, em grande parte, uma resposta à fricção inerente à relação entre os vivos e os mortos. As duas ordens de conflitos - entre os vivos, pela partilha dos bens materiais e simbólicos do defunto, e, por outro lado, entre aqueles que se encontram agora no além e os que seguem sobre a terra como seus continuadores - teriam alguma relação? A partir

(*) Universidade Federal Fluminense. mrede@uol.com.br de um estudo de caso, do reino meridional de Larsa, eu gostaria de responder afirmativamente a esta questão e sugerir, mais amplamente, algumas articulações entre o processo de transmissão dos bens e certos aspectos das práticas funerárias mesopotâmicas durante o período babilônico antigo, nos primeiros séculos do segundo milênio a.C.

\section{Transmissão patrimonial: hierarquias e privilégios}

Comecemos pela distinção feita no interior do grupo de herdeiros masculinos pelos costumes sucessórios que tendem a privilegiar um dos filhos. ${ }^{1}$ O princípio da primogenitura sucessória não parece ter sido universal na Mesopotâmia. Os

(1) As fontes não são jamais explícitas sobre este ponto e nós podemos hesitar quanto a associar a primogenitura 
REDE, M. Práticas funerárias, culto aos ancestrais e transmissão do patrimônio familiar na antiga Mesopotâmia. Rev. do Museu de Arqueologia e Etnologia, São Paulo, 14: 117-138, 2004.

dados são dispersos e pouco numerosos, provindo de fontes heterogêneas (a legislação para a Babilônia; os contratos de partilha para Larsa, por exemplo), mas nós podemos vislumbrar o seguinte quadro: ${ }^{2}$

- no norte, as práticas parecem igualitárias. No código de Hammu-rabi (1792-1750 a. C.), nenhum direito de primogenitura é previsto como princípio da partilha e os parágrafos 167 e 170 sugerem um tratamento igualitário entre os filhos da primeira e da segunda esposa (ă̌šatum), e mesmo entre os filhos da esposa principal (hîrtum) e os de uma escrava, desde que tenham sido reconhecidos pelo pai em vida. Neste caso, a única distinção reside no fato de que os filhos da esposa legítima tinham a prioridade na escolha das partes do patrimônio. ${ }^{3}$ Entretanto, se no nível das partilhas ab intestat a primogenitura biológica não cria hierarquias entre os sucessores na Babilônia, uma espécie de primogenitura pode ser instituída pela vontade do pai, que pode privilegiar materialmente seu filho predileto. ${ }^{4}$ Em Sippar, $75 \mathrm{~km}$ ao norte de Babilônia, a mesma tendência de partilhas igualitárias prevalece, mesmo se era possível conceder ao primogênito o direito de administrar a partilha. ${ }^{5}$

sucessória automaticamente ao primogênito biológico. Há todavia, indícios que levam a crer que a idade servia de base à definição das posições. Eu pressuponho esta coincidência, embora reconheça que a primogenitura possa ser criada ou alterada artificialmente, sem levar em conta a ordem de nascimento. Em todo caso, esta possibilidade, que podia concretizar-se por via testamental, por exemplo, não é um fato comum na documentação mesopotâmica. Por outro lado, eu me limito, aqui, à transmissão do patrimônio aos herdeiros do sexo masculino pela partilha post-mortem, deixando de lado a participação das filhas na sucessão, que se apresentava geralmente sob a forma do dote feito por ocasião do casamento.

(2) A impressão de um mosaico de costumes concentrados em uma região geográfica limitada não deve absolutamente surpreender: pode-se citar o caso da França, que apresentava igualmente uma enorme variedade de práticas na época moderna (ver Augustins 1989: 59ss. e Le Roy Ladurie 2002: 152ss.). Isso não impede de sugerir uma tipologia, como fizeram estes autores. Seria desejável que os estudos futuros preocupassem-se em estabelecer uma geografia consuetudinária da devolução patrimonial na Mesopotâmia.

(3) Para o problema da ausência da primogenitura no código de Hammu-rabi, ver Cuq (1929: 63); Kraus (1969a: 8ss. e 1969b: 18ss.) e Driver e Miles (1952: 331s.).
- Indo para o sul, constata-se que uma distinção impõe-se no seio do grupo de herdeiros e que um benefício material é destinado ao primogênito. Em algumas cidades meridionais, um adicional de dez por cento sobre o conjunto do patrimônio é concedido a um dos herdeiros, provavelmente o filho mais velho. ${ }^{6}$ A prática é observada em Nippur, ${ }^{7}$ em Ur, ${ }^{8}$ passando por Isin. ${ }^{9}$

- Na região de Larsa, a discriminação aprofunda-se e o privilégio torna-se maior: o primogênito recebia uma parte dupla em relação aos demais herdeiros. Na prática, isso significa que o total do patrimônio era dividido pelo número de herdeiros mais um e a parte suplementar cabia ao filho privilegiado. Este era o caso da capital do reino, Larsa, ${ }^{10}$ e também de Kutalla, pequena cidade situada a menos de $20 \mathrm{~km}$ da capital (ver Charpin 1980: 65, 71 e 173)

Tal quadro pode ser sensivelmente alterado caso se considere a diversidade de situações na periferia mesopotâmica. ${ }^{11}$ Certos autores sugeriram, aliás, que a dicotomia entre o norte e o sul mereceria ser atenuada. Sophie Lafont (1992), por exemplo, chamou a atenção para o fato de que a documentação de certas cidades forneceu contra-

(4) § 165: a-na ibila-šu ša i-in-šu mah-ru (literalmente: a seu herdeiro que agrada ao seu olho). Alguns autores viram nesta disposição uma manifestação embrionária da prática testamental, em particular se os bens adiantados ao filho preferido proviessem do conjunto do patrimônio familiar (e não de bens adquiridos especialmente para uma doação); ver, por exemplo, Miles (1954: 123s.). É preciso notar que, sendo os costumes babilônicos igualitários, tal prática constituiria não apenas uma alteração da ordem de nascimento, mas também uma verdadeira instituição da diferenciação entre os herdeiros.

(5) Ver Harris (1975: 362s. e 1976:130). Recentemente, Goddeeris (2002: 74 e 228) emitiu uma opinião contrária, mas o documento citado para apoiar sua posição (é-dubba-a, 7,25; cf. Dalley e Al-Rawi 2000) não prova que o filho mais velho teria recebido uma parte privilegiada, pois tratava-se de um filho adotado, cuja primogenitura fora criada artificialmente por um contrato e visava protegê-lo contra reivindicações futuras dos filhos naturais do casal adotivo.

(6) Para as formas de cálculo, ver Lafont (1992: 109s.) (7) Ver Stone (1991: 24), Hunter (1930: 29ss.) a propósito de OECT, 8, 17 e 18 e O'Callaghan (1954: 139s.), comentários de NBC, 8935 e de Ni,1688, publicado por Çig, Kizilyay e Kraus (1952: 16, 72 e prancha 44). Mais recentemente, Hallo (2002: 148) preferiu falar de uma 'preferential share', sem estabelecer sua dimensão. 
REDE, M. Práticas funerárias, culto aos ancestrais e transmissão do patrimônio familiar na antiga Mesopotâmia. Rev. do Museu de Arqueologia e Etnologia, São Paulo, 14: 117-138, 2004.

tos de partilha que seguem regras diferentes, o que atestaria a convivência de mais de uma tradição relativa à herança. Sem querer afastar preliminarmente esta possibilidade, eu diria que a situação contratual pode ser explicada de outro modo. A origem da diversidade documental pode estar na complexidade do processo de sucessão, que não é realizado necessariamente em uma única ocasião. Assim, uma mesma família pode realizar partilhas desiguais, nas quais o primogênito receberia integralmente sua parte adicional, e, em seguida, dividir os bens restantes de modo igualitário. ${ }^{12}$ Pode-se pensar, igualmente, na situação inversa, em que a concessão da parte suplementar era feita quando da última partilha, depois de uma ou várias divisões igualitárias. ${ }^{13}$ Em ambos os casos, a situação documental seria heterogênea, mas haveria uma única tradição de partilha, claramente discriminatória. Eu penso que é este o caso de
Larsa, por exemplo. Em todo caso, o que nos interessa, aqui, é reter o princípio de uma hierarquia entre os herdeiros, que se manifesta com maior ou menor força segundo as regiões.

\section{O caso de Larsa}

Em Larsa, os arquivos dos descendentes da família Sanum são os que fornecem os dados mais completos para o tratamento da questão da sucessão patrimonial, estendendo-se por cerca de 90 anos entre o segundo ano do reino de Sîniqî̌šam (c. 1832 a.C.) e, adentrando o período do domínio babilônico, o sétimo ano do reino de Samsu-iluna (c. 1743 a.C.). Para facilitar o acompanhamento da trajetória dos bens, fornecemos abaixo a árvore genealógica da família, tal qual o estado atual de nossas fontes permite recompor.

Família Sanum

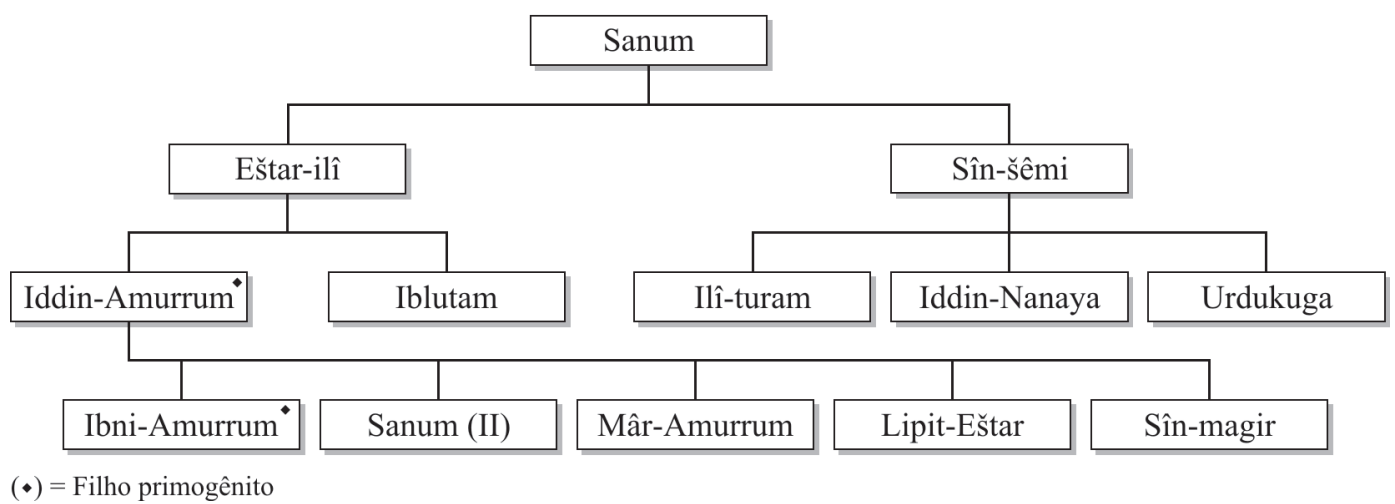

(8) Kraus (1954: 125ss.) e Charpin (1980: 35), comentando TS, 6, proveniente de Ur e que mostra uma aplicação aproximativa da regra de $10 \%$; ver também Charpin (1986 110 s..). O mesmo privilégio é encontrado em YOS, 5,148 , como demonstrou Butz (1981: 199s.) Van De Mieroop (1992: 218) pensa que a observância do adicional de $10 \%$ era mais rígida para os terrenos do que para os demais tipos de bens. Para as transmissões patrimoniais em Ur, ver sobretudo Brusasco (1999/2000: 134s..).

(9) Ver, no entanto, os argumentos contrários de Kraus (1951: 116 e 1969a: 12).

(10) Em primeiro lugar, ver Matouš 1949

(11) Assim, Boyer considerou os costumes de partilha de Mari, na região síria, mais próximos daqueles do sul mesopotâmico do que daqueles presentes na região babilônica: segundo sua interpretação do contrato de adoção ARM,8,1, o filho mais velho receberia uma parte dupla, como em Larsa. O argumento de Boyer repousa, no entanto, sobre este único documento e a interpretação de šittan como 'part double' ao invés de 'dois terços' pode ser contestada (cf. CAD, Š-3: 136). O documento em questão atesta, aparentemente, um benefício acordado ao primogênito, mas é preciso considerar que se tratava de assegurar os direitos de um filho adotivo face aos herdeiros naturais do casal. É difícil saber se estamos diante de uma situação corrente de direito de primogenitura ou de condições especiais que derivam de negociações entre as partes do contrato de adoção. A situação sucessória em Mari é, aliás, mal conhecida, em grande parte devido à ausência de arquivos familiares na documentação escavada até aqui. Em geral, a documentação palaciana informa, sobretudo, acerca da transmissão do patrimônio dos funcionários, que se revela a ocasião de inúmeras disputas entre os membros da família e o poder central, pois uma parte dos bens era de origem palacial. Inspeções e confiscos podiam ser ordenados 
REDE, M. Práticas funerárias, culto aos ancestrais e transmissão do patrimônio familiar na antiga Mesopotâmia. Rev. do Museu de Arqueologia e Etnologia, São Paulo, 14: 117-138, 2004.

Dentre os contratos provenientes dos arquivos da família, o adicional conferido ao primogênito foi geralmente respeitado. No entanto, o processo de transmissão patrimonial começou por uma repartição igualitária de bens entre os filhos de Sanum, no ano 8 de Rîm-Sîn (TCL, 10,31 de_/IV/RS 8.). Eštar-ilî e seu irmão Sîn-šêmi dividiram um pomar às margens do canal Mammi-dannat e cada um recebeu uma exata metade do terreno. Este não é o único caso de partilha igualitária documentado em Larsa (ver o Quadro 1 abaixo) e as razões da presença deste tipo de documento já foram evocadas: ou eles refletem a presença concomitante de costumes sucessórios diferentes, como propôs S. Lafont, ou, ao contrário, eles representam apenas uma etapa, provisoriamente igualitária, de um processo de partilha desigual, como penso. A presença de contratos igualitários nos arquivos de uma família que, manifestamente, praticava regularmente o privilégio de primogenitura parece confirmar a segunda explicação. ${ }^{14}$

A partir da geração seguinte, o direito de primogenitura parece ter sido sempre observado. Iddin-Amurrum e seu irmão Iblutam partilharam vários terrenos e escravos no ano 22 de Rîm-Sîn (TCL, 10,55 de_/IV/RS 22). O estado do tablete cuneiforme, bastante deterio-

pelo rei de Mari (ver Durand 2000: 184 ss.; Koppen 2002; Lafont, 2001 e Heimpel 1997: 63 ss.).

(12) Este é exatamente o encadeamento que encontramos na sucessão dos herdeiros de Sîn-šêmi, em Kutalla: uma primeira partilha, com uma dupla parte para o primogenito (TS,56), seguida, quatro anos mais tarde, de uma divisão igualitária (TS,68). Ver Charpin (1980: $64 \mathrm{ss}$.).

(13) As situações podem multiplicar-se, como mostra este documento de Ur (TS,5, datado do ano 7 de Rîm-Sîn), comentado por Charpin (1980: 37s.), no qual a regra do adicional de $10 \%$ é seguida para os terrenos, mas não para as prebendas do templo, das quais o filho mais velho recebe, pelo menos, uma parte dupla em relação ao cadete, como ocorria em Larsa. $\mathrm{O}$ documento é posterior à conquista de Ur por Larsa e podemos indagar se não houve uma contaminação, ainda que parcial, dos costumes locais de Ur pelos da nova cidade hegemônica. $\mathrm{Ou}$, então, considerando a diferença apresentada entre terrenos e prebendas, poderíamos perguntar se a transmissão das últimas não seguiriam regras próprias, de acordo com a região em que se localizava o templo. Muitos outros fatores poderiam explicar os desvios da regra. A presença exclusiva de mulheres em uma partilha igualitária de Kutalla $(\mathrm{TS}, 18)$ poderia sugerir que o rado atualmente, impede de saber as proporções exatas dos bens imóveis destinados a cada um, mas Iddin-Amurrum recebeu 11 escravos enquanto que Iblutam recebeu apenas 5, uma aplicação tão próxima quanto possível do princípio da parte dupla, em se tratando de bens indivisíveis por natureza. Além disso, o primogênito recebeu os objetos de culto familiar, totalmente ausentes da parte do caçula (eu retornarei à questão). A posição privilegiada de Iddin-Amurrum foi reforçada por uma segunda partilha, trinta e oito anos mais tarde, logo após a chegada dos conquistadores babilônios: $:^{15}$ ele recebeu $353 \operatorname{sar}\left(12.355 \mathrm{~m}^{2}\right)$ do pomar familiar, contra $176 \operatorname{sar}\left(6.055 \mathrm{~m}^{2}\right)$ dados a Iblutam. ${ }^{16}$ É interessante ver como a lógica matemática da partilha impõe-se de modo estrito: como as contas não são exatas, o primogênito recebe uma pequena parcela a mais do que tinha direito e é obrigado a pagar um siclo de prata (c. 8 gramas) como compensação ao seu irmão caçula (TCL, 11,141: 8-11).

Um último registro concerne esta geração da família Sanum (TCL, 10,30 de_/X/RS 8). O contrato registra apenas a parte do patrimônio concedida a um dos herdeiros, Iddin-Amurrum. Trata-se de vários lotes de terrenos cujo recapitulativo indica estarem situados nas bordas

(14) A menos que nós pensemos em uma terceira possibilidade, fundada sobre a cronologia dos documentos: a família teria praticado a partilha igualitária até a geração dos filhos de Sanum e, depois, a partir do ano 22 de Rîm-Sîn, teria adotado práticas sucessórias discriminatórias. Pessoalmente, creio que esta solução seja pouco provável. Em Kutalla, tem-se também um exemplo de práticas alternativas no interior de uma mesma família, a de Sîn-šêmi, separadas por apenas quatro anos; é interessante notar que, neste caso, a ordem é inversa daquela encontrada na família Sanum: primeiramente, uma partilha diferenciada (TS,56 do ano 42 de Hammu-rabi) e, depois, uma partilha igualitária (TS, 68 do ano 4 de Samsuiluna), o que enfraquece a hipótese de que os costumes hereditários tenham sido alterados no reino de Larsa devido à conquista babilônica. Ver Charpin (1980: 64s.). (15) TCL, 11,141 de_/III/Ha 1, ou seja, do primeiro ano de reinado de Hammu-rabi em Larsa, não em Babilônia. É muito provável que esta partilha tenha acontecido algum tempo antes, sem ter sido posta por escrito; com a chegada dos babilônios, os dois irmãos teriam tomado suas precauções e registrado a operação. Uma outra possibilidade é que o antigo contrato, com a fórmula de datação e o juramento em nome do rei deposto tenha 
REDE, M. Práticas funerárias, culto aos ancestrais e transmissão do patrimônio familiar na antiga Mesopotâmia. Rev. do Museu de Arqueologia e Etnologia, São Paulo, 14: 117-138, 2004.

do rio Tigre. Se não se trata de uma doação paterna e sim de uma verdadeira partilha, como parece indicar o formulário verbal e a utilização da expressão ' $h a-l a$ ' (parte de), seria preciso supor que a parte de Iblutam fora registrada em um outro tablete, hoje perdido. ${ }^{17}$ É preciso acrescentar que outras formas de transferência entre as gerações podiam igualmente servir a privilegiar o primogênito, excluindo os cadetes, como uma venda feita do pai para o filho: parece que este foi, justamente, o caso de uma transferência de terreno entre Eštar-ilî e seu filho IddinAmurrum. ${ }^{18}$

No ano 40 de Hammu-rabi, houve uma grande divisão de bens entre os cinco filhos de Iddin-Amurrum, pertencentes à última geração conhecida da família Sanum (TCL, 11,174 de 4/ VI/Ha 40). São partilhados três tipos de bens: a casa familiar, os terrenos rurais e o mobiliário em madeira (mesas, cadeiras, leitos, portas). Em cada uma das categorias, o privilégio do primogênito foi respeitado.

Mesmo tendo sido bastante abrangente, esta partilha não incluía todos os bens fundiários da família e alguns pomares ainda permaneceram indivisos por seis anos. Foi apenas no ano 4 de Samsu-iluna que eles foram finalmente repartidos pelos cinco filhos de Iddin-Amurrum
(TCL,11,200 de 20/III/Si 4). Esta partilha certamente não foi igualitária, ${ }^{19}$ mas nenhuma regra pode ser precisada: o início do tablete está quebrado, o que nos impede de conhecer, justamente, a parte recebida pelo primogênito, Ibni-Amurrum, primeiro da lista. Aliás, as partes dos demais irmãos também não foram exatamente iguais, sem que possamos saber o motivo exato. ${ }^{20}$

Parece que Ibni-Amurrum faleceu no ano 7 de Samsu-iluna sem deixar herdeiros. Seus bens seguiram, então, uma transmissão colateral e foram partilhados por seus irmãos. ${ }^{21} \mathrm{O}$ contrato redigido neste momento não nos permite saber se algum critério de favorecimento foi seguido, pois as partes de cada irmão não foram detalhadas. Esta é, alias, uma situação sobre a qual não temos informações claras: nas regiões que praticavam normalmente a partilha diferenciada, o princípio de precípuo era também válido nos casos de devolução colateral entre os irmãos do morto?

Além da família Sanum, o privilégio material destinado a um dos filhos repete-se freqüentemente nos contratos de Larsa, mesmo se é possível constatar também divisões igualitárias. Muitas vezes, o estado da documentação não permite extrair uma regra. Aqui está o quadro completo:

outros exemplos: o primeiro é YOS,5,106 (_/I/RS 37) que registra apenas a parte de Ilî-ippalsam (os terrenos situavam-se em Larsa e em Rahabum, na região larseana; cf. RGTC,3: 194; ver Kraus 1951: 97, n. 18); o segundo exemplo vem da época de dominação babilônica: PSBA,29: 23, para o qual, apesar das lacunas no tablete, pode-se assumir sem risco que apenas a parte de Lipit-Ea, neto do conhecido Balmunamhe, foi registrada.

(18) TCL, 10,42 de_/II/RS 16, seis anos anterior, então, à primeira partilha em que Iddin-Amurrum e Iblutam são citados explicitamente. As vendas ao primogênito antes da partilha podem ser vistas como mecanismos eficazes de concentração do patrimônio familiar, sendo, ao mesmo tempo, suficientemente aceitáveis pelo conjunto de cadetes (ao menos, mais aceitáveis do que uma doação), pois eles não são completamente excluídos uma vez que partilharão o resultado da venda. Para as estratégias familiares visando salvaguardar o patrimônio da pulverização, às expensas das regras de partilha, ver Bourdieu (1972: 1114 ss..).

(19) A proposição de Matouš de traduzir a expressão ina mitgur-šunu por "par portions égales" não deve ser retida; ver: Dombradi 1996: 98: in gegenseitigen Einvernehmen. 


\section{Quadro 1: Precípuo nas partilhas de Larsa}

\begin{tabular}{|c|c|c|c|c|}
\hline & $\begin{array}{l}\text { Presença do } \\
\text { precípuo }\end{array}$ & Partilha igualitária & Indeterminado & Observaçöes \\
\hline \multicolumn{5}{|l|}{ Família Sanum } \\
\hline $\begin{array}{l}\text { TCL, } 10,31 \\
\end{array}$ & & $\mathrm{X}$ & & \\
\hline TCL, 10,30 & & & $\mathrm{X}$ & Registro de parte única \\
\hline TCL, 10,55 & $\mathrm{X}$ & & & \\
\hline TCL, 11,141 & $\mathrm{X}$ & & & \\
\hline TCL, 11,174 & $X$ & & & \\
\hline TCL, 11,200 & $\mathrm{X}$ & & & \\
\hline TCL, 11,218 & & & $\mathrm{X}$ & \\
\hline \multicolumn{5}{|l|}{ Outras famílias } \\
\hline Riftin,2 & $\mathrm{X}$ & & & \\
\hline YOS, 8,98 & & $\mathrm{X}$ & & \\
\hline YOS $, 8,88$ & $X$ & & & \\
\hline YOS, 5,106 & & & $\mathrm{X}$ & Registro de parte única \\
\hline VS, 13,90 & $\mathrm{X}$ & & & \\
\hline TCL, 11,224 & & & $\mathrm{X}$ & \\
\hline YOS, 8,167 & $\mathrm{X}$ & & & Ver obs. n. 4 abaixo \\
\hline PSBA,29:23 & & & $\mathrm{X}$ & Registro de parte única \\
\hline YOS, 8,83 & & $\mathrm{X}$ & & \\
\hline PTS,2187 & $\mathrm{X}$ & & & $\begin{array}{l}\text { Rascunho ; não contém o } \\
\text { nome dos co-herdeiros }\end{array}$ \\
\hline $\begin{array}{l}\text { Percentagem sobre } \\
\text { o total de casos }\end{array}$ & $52,94 \%$ & $17,65 \%$ & $29,41 \%$ & \\
\hline
\end{tabular}

Observações: 1) YOS,8,133, citado por Matouš (1949: 154) como sendo um caso indeterminado, provém, na verdade, de Ur e a parte suplementar é de 10\%, como esperado para esta cidade; 2) YOS,8,148, citado por Matouš como sendo uma partilha igualitária pertence a uma família originária de Ur (caso tratado por Butz 1981) e a parte suplementar de 10\% é, grosso modo, respeitada; 3) no documento Šumer et Akkad, 166, as medidas dos terrenos estão quase ilegiveis, sobretudo no caso do primeiro co-herdeiro (primogênito?); Leemans (1955: 121) restituiu medidas idênticas para os três herdeiros, supondo uma partilha igualitária; no mesmo sentido cf. Charpin (1986: 132), que se baseou no fato de que a casa da familia, situada em Ur, seria a mesma que aparece no registro RA,14,95; 4) L. Matouš considerou que YOS, 8,167 faz parte das partilhas igualitárias; no entanto, o formulário do documento induziu-o a cometer um erro: de fato, o patrimônio foi dividido em duas partes iguais, mas a segunda parte foi destinada a dois dos irmãos, assim cada um recebeu a metade da parte do irmão primogênito, como era a regra em Larsa.

(20) A trajetória deste terreno no interior da família não é totalmente clara, mas a seguinte reconstituição pode ser sugerida: quando de uma primeira partilha (cujo contrato desapareceu, mas que é citado nas linhas 16-21 de TCL, 11,200), Iddin-Amurrum e seu irmão Iblutam haviam dividido um pomar; as duas parcelas seguiram caminhos diferentes: o lote transmitido a Iblutam foi parcialmente vendido a seu sobrinho Ibni-Amurrum no ano 3 de Samsu-iluna (TCL, 11,198), mas Iblutam conservou uma parte do terreno, continuando como vizinho de IbniAmurrum; a parcela de Iddin-Amurrum permaneceu indivisa pelos seus filhos, sendo partilhada um ano depois (TCL, 11,200). Isto explica por que, neste último documento, Iblutam estava registrado como testemunha (linha 33'), imprimindo nele seu selo: sendo mais novo, ele sobreviveu ao seu irmão Iddin-Amurrum e possuía ainda alguns terrenos nos domínios fundiários da família. De fato, certos dados cadastrais em comum (o fato de Waradilišu ser um dos vizinhos e de uma estrada bordejar o pomar) confirmam a relação entre os dois casos; a ausência de Iblutam como vizinho na partilha (TCL,11,200) pode ser facilmente explicada pelo estado lacunar do tablete, pois ele era justamente o vizinho de IbniAmurrum, cujo registro da parte falta hoje no documento. 
REDE, M. Práticas funerárias, culto aos ancestrais e transmissão do patrimônio familiar na antiga Mesopotâmia. Rev. do Museu de Arqueologia e Etnologia, São Paulo, 14: 117-138, 2004.

Os contratos de partilha mesopotâmicos limitam-se, em geral, a distribuir bens. No entanto, o privilégio destinado ao primogênito não se restringia às vantagens materiais: a desigualdade no nível dos bens era reforçada por uma sucessão discriminatória. É certo que estamos muito mal informados sobre o modo como o pai é substituído em sua posição social e no exercício de sua autoridade. Se, por um lado, a fragmentação da casa em diversas subunidades, implicada pela inclusão de todos os filhos masculinos na partilha, sugere uma multiplicação dos centros de decisão, com cada nova casa tendo seu próprio chefe, por outro, nada impedia que houvesse uma certa concentração de poder. O acúmulo da autoridade moral pelo primogênito pode ter efeitos seja no interior da família seja em seu exterior, isto é, nas relações com a comunidade. Ao contrário das vantagens materiais, o poder herdado tem contornos menos definidos e seu exercício dependerá, em grande parte, da habilidade do primogênito em traduzir na prática um atributo que é apenas potencial. No fim das contas, a autoridade é menos um bem que se herda do que uma capacidade construída nas relações com outros membros da família e com a sociedade em geral. Sendo mais abstrata, esta diferença de poder escapa do formulário dos contratos de partilha e, por conseqüência, de nosso campo de visão.

Alguns outros elementos do privilégio de sucessão podem, no entanto, ser notados. Nós sabemos, por exemplo, que Ibni-Amurrum herdou o selo-cilindro de seu pai. Em uma série de contratos datados da época da ocupação babilônica, ele imprime o selo de Iddin-Amurrum para legitimar suas próprias transações comerciais. ${ }^{22}$ A maior parte desses contratos refere-se aos negócios de Ibni-Amurrum com o palácio: são recibos de produtos (peixes, lã, tâmaras, cebolas) entregues pelo palácio para comercialização e que deveriam ser pagos em um certo prazo. Ibni-Amurrum foi, então, um mercador (tamkârum) a serviço do palácio. Parece que seu pai Iddin-Amurrum teria exercido a mesma função ${ }^{23} \mathrm{e}$, assim, não seria absurdo supor que tal posição junto ao palácio tivesse sido herdada pelo filho primogênito ao mesmo tempo que as vantagens patrimoniais.

\section{Tumbas domésticas}

É na realização dos rituais familiares que se pode procurar uma outra sorte de diferenciação entre o primogênito e os demais filhos. Se os rituais têm seus fundamentos nas concepções mitológicas, sua eficácia social depende largamente de uma performance, de um conjunto de gestos e palavras que têm a capacidade de atualizar o mito no momento presente, de traduzir as evocações mais abstratas do relato mítico em uma realidade mais tangível. Esta representação ritual é, pois, uma questão de tempo, pois ela dota de temporalidade certas categorias mitológicas que são, por definição, atemporais ou pouco afetadas pela duração, mas ela é também uma questão de materialidade espacial: o ritual supõe o engajamento do próprio
Matouš (1949: 168) fez, corretamente, a aproximação entre os dois casos, mas considerou, de maneira equivocada a meu ver, que TCL, 11,200 registraria "le règlement d'une querelle des copartageants", à semelhança de TCL, 11,218 (ver a nota seguinte).

(21) TCL,11,218 de_/II/Si 7. Matouš (1949: 171) entendeu o caso como a resolução de uma disputa entre dois irmãos co-herdeiros, Ibni-Amurrum e Lipit-Eštar, o que teria permitido a divisão de terrenos entre eles. De fato,

Matouš considerou que as linhas 1-8 do tablete formavam a descrição da primeira parte (ha-la), concedida a LipitEštar e que as linhas 10-13 indicariam os terrenos cedidos a Ibni-Amurrum. Entretanto, vários elementos, constatados em uma verificação do tablete no Museu do Louvre, me permitem propor uma outra interpretação do documento: 1) na linha 9, não há espaço suficiente para a expressão ha-la e o sinal cuneiforme, mesmo muito apagado, é claramente um $\grave{u} ; 2$ ) na linha 10 , não se tem a descrição do primeiro terreno da parte de um segundo herdeiro, como pensou Matouš, mas o recapitulativo dos terrenos citados nas linhas $1-9 ; 3$ ) ora, este terreno nos é conhecido: tratase do pomar nas margens do canal Išme-Enlil, recebido por Ibni-Amurrum em uma partilha anterior (TCL, 11,174); 4) um último elemento diz respeito à cronologia da partilha: TCL, 11,218 data exatamente do fim dos arquivos de Ibni-Amurrum, o mês II de Si 7; parece, então, que este documento representa, na verdade, a divisão dos terrenos de Ibni-Amurrum, morto recentemente, pelos seus irmãos (o singular "seu irmão" na linha 17 parece indicar, simplesmente, que o documento em questão era uma cópia destinada a apenas um dos irmãos; na linha seguinte, a frase encontra-se no plural: $i$-na mi-it-gur-šunu $i-z u-z u)$.

(22) Os contratos em que o selo de Iddin-Amurrum é utilizado por seu filho são: TCL, 11,172, 193, 195, 199, 200, 208 e 210 
REDE, M. Práticas funerárias, culto aos ancestrais e transmissão do patrimônio familiar na antiga Mesopotâmia. Rev. do Museu de Arqueologia e Etnologia, São Paulo, 14: 117-138, 2004.

corpo dos oficiantes, a manipulação de objetos litúrgicos, o ancoramento em um território, por vezes considerado sagrado. Tais características são particularmente visíveis nos cultos mortuários, nos quais a presença dos restos mortais dos ancestrais serve para delimitar um espaço cerimonial. ${ }^{24}$

Nessa materialidade do culto prestado aos ancestrais existe um primeiro vínculo com $o$ processo de devolução. Os objetos rituais, os sacra, eram partilhados entre os herdeiros ou, em caso de discriminação como em Larsa, eram transmitidos preferencialmente ao primogênito. $\mathrm{O}$ mesmo ocorria com os espaços funerários, sobretudo em situações em que as tumbas estavam fisicamente associadas as casas. Assim, em Larsa, como alhures na Mesopotâmia, a divisão do espaço residencial significava também uma partilha do espaço ritual da família e a vantagem material do primogênito era acrescida de um controle exclusivo ou preferencial sobre o patrimônio simbólico ligado aos ancestrais

Um segundo elemento concerne aos próprios atores implicados: o processo de devolução coloca os ancestrais na posição de doadores de bens e os descendentes no papel de receptores de bens. $\mathrm{O}$ culto dos ancestrais acrescenta, assim, uma terceira dimensão a um processo geral de substituição das gerações: de início, a sucessão biológica; depois, a sucessão patrimonial; o culto mortuário é um terceiro procedimento sucessório, que permite redefinir os papéis dos agentes sociais, agora separados pela barreira da morte. ${ }^{25}$ Dito de outro modo, trata-se de um acerto de contas simbólico entre as gerações, o que permite dar uma resposta à tensão instalada pela separação radical entre os vivos e os mortos promovida pelo trespasse.

A importância desses dois aspectos deriva do fato de a sucessão não se limitar a uma questão de transmissão de bens, mas implicar um novo arranjo das respectivas posições dos atores sociais. $\mathrm{O}$ desaparecimento de alguns destes atores não elimina, bem ao contrário, a necessidade de novas composições e enseja uma situação crítica à qual as regras de herança devem fazer face. Por outro lado, do ponto de vista do sistema doméstico, a perpetuação da unidade de produção e consumo depende de uma solução de continuidade que impeça que a morte do chefe da família tenha como resultado a extinção dos direitos de acesso aos bens e, particularmente, ao solo. O problema é que essa solução não é natural $\mathrm{e}$ a existência de vários casos em que as tensões engendram uma resistência à transmissão e, no limite, levam à destruição dos bens (J. Goody 1962: 306s.), lembra-nos que a perpetuação do grupo doméstico é uma questão delicada e exige negociações constantes.

Tais observações têm um caráter genérico, mas não universal: elas delimitam certos elementos que são encontrados em sociedades sedentarizadas, como a Mesopotâmia antiga, mesmo se nesta os
(23) O único indício documental é, no entanto, YOS, 8, 102 (datado de 11/II/RS 28), onde um certo Iddin-Amurrum é citado como sendo tamkârum: 1 . 7: ${ }^{\mathrm{I}}{ }^{\mathrm{H}}$-din- ${ }^{\mathrm{d}}$-mar-tu dam-gàr. Leemans (1950: 50) inclui Iddin-Amurrum em sua lista de mercadores de Larsa da época da independência de Larsa, acrescentando que algumas de suas atividades (como o empréstimo de prata registrado em TCL, 10,75) faziam parte dos negócios típicos desta atividade (p. 58). A atestação do título é, sem dúvida, de menor importância, como demonstra o próprio caso de Ibni-Amurrum, que nunca é chamado de tamkârum nas fontes, embora a natureza de seus negócios não deixem dúvidas sobre a sua inclusão na categoria.

(24) A exemplo de Schmidt (1996: 5s.), eu considero cultos mortuários (mortuary cult) o conjunto de ritos executados para os mortos de um modo regular, implicando seu cuidado, alimentação ritual e veneração, por oposição aos ritos funerários (funerary rites), que correspondem ao tratamento dispensado aos restos mortais no momento da morte (burial rites) e aos cultos que se sucedem imediatamente aos funerais (mourning rites). Eu entendo igualmente que o culto aos ancestrais (ancestor worship)

\footnotetext{
é um elemento indispensável, ao menos na Mesopotâmia, para a constituição de um verdadeiro culto mortuário que se prolongue além da circunstância mais limitada das exéquias fúnebres. O ritual do kispum corresponde, grosso modo, a essa relação mais durável implicada pelos cultos mortuários, mesmo se se pôde demonstrar que, eventualmente, ele pode estar também associado aos ritos funerários propriamente ditos (ver Tsukimoto 1980: 129s.). (25) Se, do ponto de vista demográfico, esta barreira se desloca normalmente dos mais velhos para os mais jovens, várias situações podem provocar sobressaltos, como a morte prematura de um primogênito, por exemplo. Nestes casos, alguns mecanismos intervêm a fim de superar o problema: a transferência da condição de primogênito a um benjamim, ou mesmo a uma filha, ou ainda a adoção. Por outro lado, do ponto de vista simbólico, a separação entre o mundo dos mortos e dos vivos é menos nítida e, ao menos parcialmente, reversível: a possibilidade de um retorno dos mortos, tópico recorrente da mitologia mesopotâmica, é constantemente objeto de procedimentos mágicos que visam impedi-lo.
} 
REDE, M. Práticas funerárias, culto aos ancestrais e transmissão do patrimônio familiar na antiga Mesopotâmia. Rev. do Museu de Arqueologia e Etnologia, São Paulo, 14: 117-138, 2004.

componentes nômades e seminômades eram importantes, mas que não correspondem à situação das sociedades de caçadores-coletores, por exemplo. A apropriação social do espaço manifesta-se de modo bastante diverso segundo os casos, e a organização do espaço funerário, em particular, sofrerá as conseqüências. No segundo tipo de sociedade, a situação extrema é a completa ausência de tumbas, o que, por vezes, é o resultado da própria ausência de funerais (Désvaux 1994: 64) ${ }^{26} \mathrm{Na}$ maior parte do tempo, a consagração de um território pela morte de um membro do grupo implica uma exclusão, um distanciamento: as pessoas partem deixando para trás um espaço poluído pela morte. Evidentemente, a própria contaminação do ambiente por um corpo não inumado impunha o abandono e a mobilidade deste tipo de grupo permite uma resposta eficaz ao problema. De um modo geral, pode-se dizer que, entre os caçadores-coletores, as práticas funerárias não operam um ancoramento territorial consistente, tendendo, ao contrário, a estimular o deslocamento. ${ }^{27}$

$\mathrm{Na}$ antiga Mesopotâmia, o processo de neolitização levou a uma situação muito diferente em que a sedentarização do vivos implicou igualmente um enraizamento dos mortos. As inumações e a constituição dos cemitérios são sua expressão mais concreta. O fenômeno das transformações das práticas funerárias durante o período $\mathrm{Neolitico}^{28}$ é bastante complexo e eu me limito a evocar uma modalidade mais estreitamente ligada às questões tratadas aqui: a associação entre a habitação e as tumbas.

Na Mesopotâmia, as práticas funerárias são variadas, ${ }^{29}$ mas as diversas formas de sepultamento predominam: com ou sem esquifes (sarcófagos ou, mais correntemente, recipientes cerâmicos); $\mathrm{o}$ corpo depositado diretamente na terra, envolto em tecidos ou ainda cercado de uma estrutura em pedra, cacos de argila ou simplesmente terra batida; inumação em fossas, em sepulcros subterrâneos ou mesmo nos pântanos, como no sul sumério - uma prática seguida até um período tardio por alguns reis do primeiro milênio. A cremação, ao

(26) É preciso, no entanto, levar em conta a dificuldade de identificar os contextos funerários paleolíticos e de diferenciar os simples abandonos de corpos dos sepultamentos; para um tratamento do problema com um repertório dos casos conhecidos, ver Fedele (1994: 28 ss.) contrário, parece ter sido uma prática pouco corrente. ${ }^{30}$ A este quadro, somam-se os dados de uma topografia funerária que se pode resumir na oposição entre as sepulturas extra muros e as sepulturas intra muros. Nesta última categoria, bastante típica da Mesopotâmia, mas longe de lhe ser exclusiva, encontra-se a inumação nas tumbas situadas no subsolo das casas. A prática é atestada bastante cedo na região, ao menos a partir da época de Hassuna (VI milênio, equivalente ao período de Obeid no Sul do vale) e perdurará até o fim do primeiro milênio. ${ }^{31}$

Em uma época mais próxima daquela que nos interessa aqui, as inumações sob as casas são bastante difundidas durante o terceiro e inícios do segundo milênios. ${ }^{32} \mathrm{O}$ quarteirão residencial de Ur é um caso bastante representativo. ${ }^{33}$ Outros exemplos são atestados igualmente em $\mathrm{Girsu}^{34} \mathrm{e}$, em escala mais limitada, em Sippar. ${ }^{35}$

Em Larsa, o mesmo costume marcou o quarteirão residencial nordeste da cidade, datado da mesma época de nossos arquivos epigráficos, e pode ter sido generalizado (ver Hofman 1997:

(27) Eu forço intencionalmente o traço deste quadro a fim de melhor estabelecer o contraste com a situação mesopotâmica. Certamente, as sociedades de caçadorescoletores estabelecem relações específicas com o espaço e não é necessário supor, por causa do deslocamento contínuo, uma completa ausência de ligação no nível da ocupação concreta do território ou da imagem que tais sociedades formam sobre a ocupação territorial; simplesmente, a prática e a representação que lhes são próprias diferem daquelas das sociedades sedentárias. Em todo caso, é somente a partir de sociedades de tipo neolítico que a relação com o espaço ancestral será expressa fisicamente (tumbas, monumentos etc.) e que a morte será incorporada como um elemento importante da paisagem humana (ver a este propósito Pollard 1999: 88 s.). No mais, as situações intermediárias são numerosas e inspiram nuanças nas comparações: basta lembrar que, mesmo nas sociedades urbanas contemporâneas, as formas de espacialização são cada vez mais definidas por uma composição entre as mobilidades e os ancoramentos e que o conceito tradicional de sedentarizacão tornou-se manifestamente inoperante para a análise de situações em que a articulação entre o local e o global se mostra de modo até então inesperado (ver os estudos reunidos por Hirschhorn e Berthelot 1996, em particular os capítulos de Mormont e Remy).

(28) Ver, em geral, Forest (1983).

(29) Para uma tipologia, ver o artigo de Eva Strommenger no Reallexikon der Assyriologie, volume 3, s.v. 'Grab', assim como Barrelet (1980: 7 ss.) 
REDE, M. Práticas funerárias, culto aos ancestrais e transmissão do patrimônio familiar na antiga Mesopotâmia. Rev. do Museu de Arqueologia e Etnologia, São Paulo, 14: 117-138, 2004.

64 ss. e Calvet 1997: 89 ss. e 109 ss.). Durante as duas últimas campanhas de escavação (em 1987 e 1989, sob direção de J.-L. Huot), os arqueólogos trouxeram à luz duas grandes residências de um conjunto que podia chegar a mais de trinta casas. Os dois exemplares escavados contavam com caves funerárias que foram, sem dúvida, construídas ao mesmo tempo que o próprio edifício, integrando-se completamente à sua arquitetura ${ }^{36}$ Nos dois casos, as tumbas subterrâneas são estruturas bem planejadas e executadas, em tijolos cozidos, e cujas entradas pelo interior das casas se fazia a partir de cômodos de acesso limitado.

Na casa B 27 (cuja escavação começou em 1987 e foi concluída em 1989) a cave funerária, com duas sepulturas atestadas, encontrava-se no subsolo do cômodo 3 , ao longo do ângulo nordeste. A partir de cada uma das duas entradas da casa (1 e 12), era preciso atravessar cinco ou quatro cômodos, respectivamente, para chegar ao local de acesso às tumbas. Na segunda casa, B 59 (inteiramente escavada em 1989), o sepulcro situava-se sob o cômodo 17, no ângulo sudeste, diametralmente oposto à entrada (1) e o acesso era igualmente dificultado pelas possibilidades de circulação no interior, que exigia a travessia de

(30) No entanto, algumas escavações recentes parecem sugerir que a cremação foi mais difundida do que se tinha pensado até aqui. Mesmo se ela permanece largamente minoritária no conjunto e limitada à zona hitito-levantina, ela penetrou na região siro-mesopotâmica tardiamente, a partir do final do segundo milênio, num movimento cuja influência hitita (portanto indo-européia) é praticamente certa. Na Síria, um exemplo é a grande necrópole de tumbas de incineração de Tell Shioukh Faouqâni (antiga Burmarina) do início da Idade do Ferro (ver Bachelot et alii 2001: 9 ss.). Por vezes, a prática de incineração aparece de modo residual em contextos majoritários de inumação, como em Tell-Sabi-Abyad, no norte da Síria, durante o Bronze Recente (Akkermans e Rossmeisl 1990 13 ss.), outras vezes, ela acaba por ter uma importância considerável, como na necrópole de Hama, no início da Idade do Ferro (Riis 1948: 27 ss.), ou em Deve Hüyük (século VIII) na região de Karkemish (Moorey 1980: 5 ss.). $\mathrm{Na}$ Mesopotâmia, os exemplos são esporádicos e, em geral, atestados por escavações antigas: para Aššur na época neo-assíria, ver Haller (1954: $52 \mathrm{~s}$.) e, para a Babilônia, ver Reuther (1926: 189) e Baker (1996: 219). (31) Para as práticas funerárias mesopotâmicas na época proto-histórica, ver em particular Forest 1983. As inumações sob as estruturas de habitação são atestadas em vários sítios deste período; alguns exemplos: Yarim-Tepe, na região de cinco cômodos. Nos dois casos, os setores funerários eram compostos do mesmo modo tripartite: um pequeno hall de entrada, o grande espaço sobre as caves e um pequeno nicho anexo. Tanto em B 27 como em B 59, os cômodos que davam acesso às sepulturas eram de dimensões elevadas, ocupando o segundo lugar, atrás apenas do espaço central. ${ }^{37}$

\section{Cultos mortuários e primogenitura}

A presença dos sepulcros sob as casas serviu para reforçar ainda mais o costume larseano da primogenitura. Com efeito, certos dados sugerem que, quando da partilha, o filho mais velho era o destinatário privilegiado dos espaços rituais da residência paterna: ${ }^{38}$ no contrato que registra a divisão do patrimônio de Iddin-Amurrum entre seus filhos, um santuário é acrescentado à parte que cabia ao primogênito Ibni-Amurrum. ${ }^{39}$ Além disso, de um modo geral, a concentração de recursos fundiários nas mãos do primogênito, por intermédio de aquisições feitas aos cadetes, permitia que ele consolidasse sua posição de controle dos espaços sagrados do grupo.

Hassuna (Merpert, Munchaev e Bader 1981), Khajaf, a antiga Tutub, no vale do Diyala (Henrickson 1981: 77); Kish, na região babilônica (Algaze 1983/4); e também no sul: AbuSalabih. A associação entre os sepulcros subterrâneos e o espaço de habitação é demonstrada ainda por alguns dos sítios mais prestigiosos da literatura arqueológica, como Çatal-Höyük, por exemplo. Para os períodos tardios do primeiro milênio, na Assíria e em Babilônia, ver Castel (1992: 106 ss.) e, para a Babilônia, Baker (1996: 218).

(32) Para o terceiro milênio, ver Crawford (1977: $37 \mathrm{~s}$.) e Laneri (1999). A tese de Laneri, que considera a multiplicação do fenômeno no início da Idade do Bronze como uma característica do período, na esteira do esboroamento do chamado 'sistema urukiano' do quarto milênio, merece, entretanto, ser relativizada em função de uma bem atestada continuidade arqueológica neste domínio. Por outro lado, Laneri contestou corretamente a idéia, comum entre certos arqueólogos (Woolley 1952, por exemplo), segundo a qual esta prática corresponderia a um estágio primitivo, substituído em seguida por inumações regulares, em cemitérios distantes das zonas de habitação (p. $221 \mathrm{~s}$.). Como Laneri demonstrou, o terceiro milênio assistiu a um desenvolvimento seja de tumbas intra muros, seja de cemitérios extra muros, ou ainda de verdadeiras necrópoles, situadas fora dos centros residenciais (p. 222). Para a 


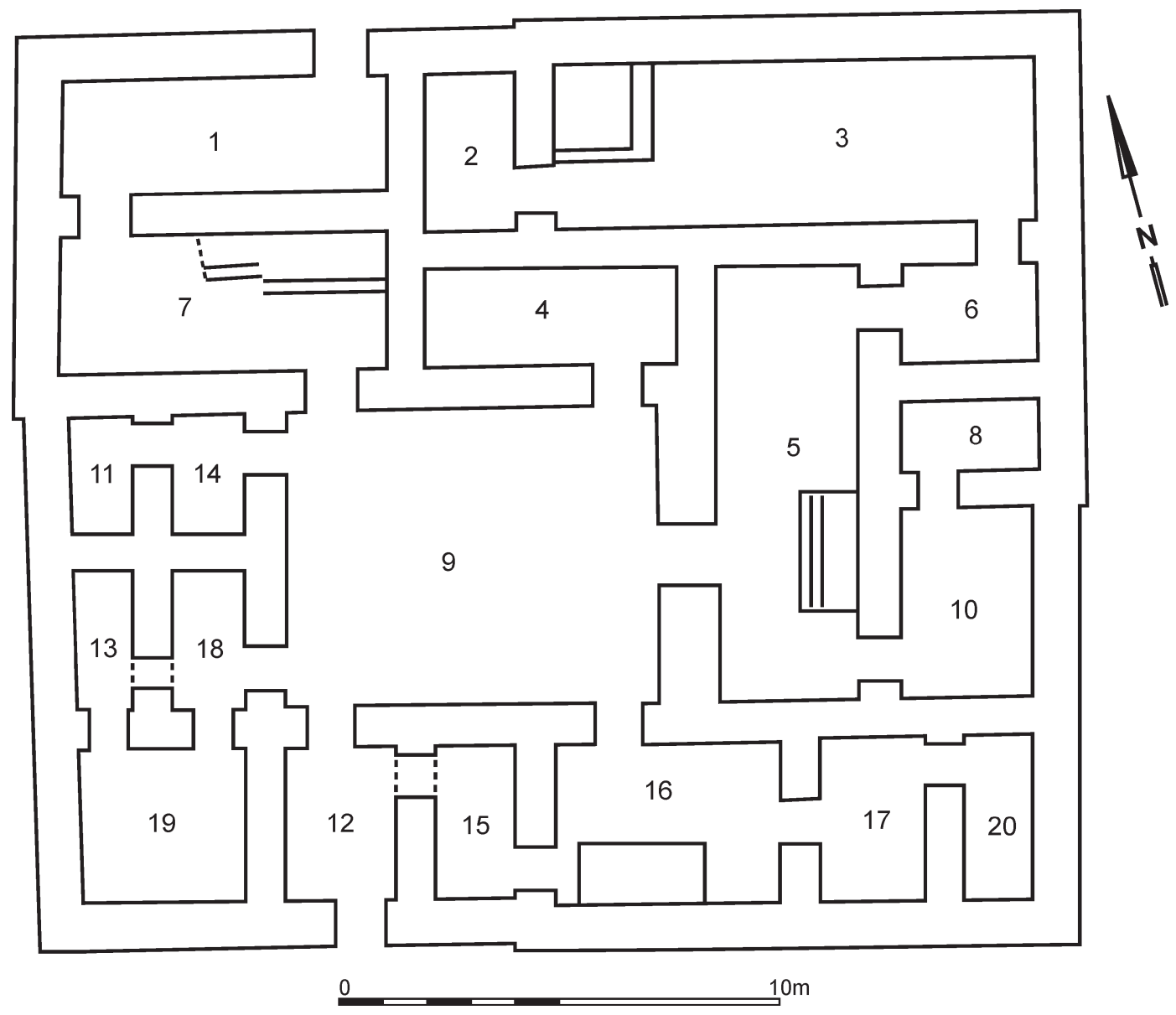

Plano da casa B 27 (segundo Calvet 2003).

presença de tumbas sob as casas na região síria, ver JeanMarie (1990: 304) e, para a zona do Jerablus-Tahtani, Peltenburg (1995: 71) e Peltenburg et alii (1996: 10 s.). É preciso notar, por fim, que, em certos casos, os autores nem sempre compreenderam a importância das caves funerárias como um elemento da arquitetura doméstica, como é o caso do trabalho de Robert 1995 sobre as residências do Período Dinástico Arcaico.

(33) Ver o volume 7 de The Excavations at Ur de Leonard Woolley (1976: 33 ss. Catálogo pp. 194 ss.), Luby (1990: 70 ss.), Battini-Villard (1999: 211 ss.) e, em último lugar, Brusasco (1999/2000: $71 \mathrm{ss}$.) cuja análise estatística dos dados tende a confirmar as idéias preliminares de Woolley quanto à identificação das capelas com os loci de concentração dos elementos cultuais (altares, nichos, pedestais, terracotas votivas etc.) e sua ligação com as caves no subsolo, o que reforça o caráter funerário das estruturas cultuais domésticas. Por outro lado, o estudo conjunto dos dados arqueológicos e epigráficos feito por Charpin (1986: 192 ss.) reforça a associação entre os domínios residenciais (de membros do clero) e as práticas funerárias (por exemplo, a presença de listas de oferendas aos defuntos dos sacerdotes-entum, cf. p. 208). O caso do giparum da grande sacerdotisa do deus Nanna é interessante, pois nos informa sobre um tipo de caso em que a construção está a meio caminho entre a função residencial e a função religiosa. Charpin notou que sua organização reproduz aquela das grandes residências de Ur, associando o espaço de habitação, a capela e as caves subterrâneas, as diferenças sendo apenas de escala (p. 218 e 220).

(34) Genouillac (1936: $14 \mathrm{~s}$.) havia considerado que a estrutura fazia parte de um templo da Nanše, que dataria do terceiro milênio. Posteriormente, Parrot (1948: 276 ss.) estabeleceu o caráter doméstico da construção e Gasche (1978: 80) propôs uma datação paleobabilônica (inícios do segundo milênio). 


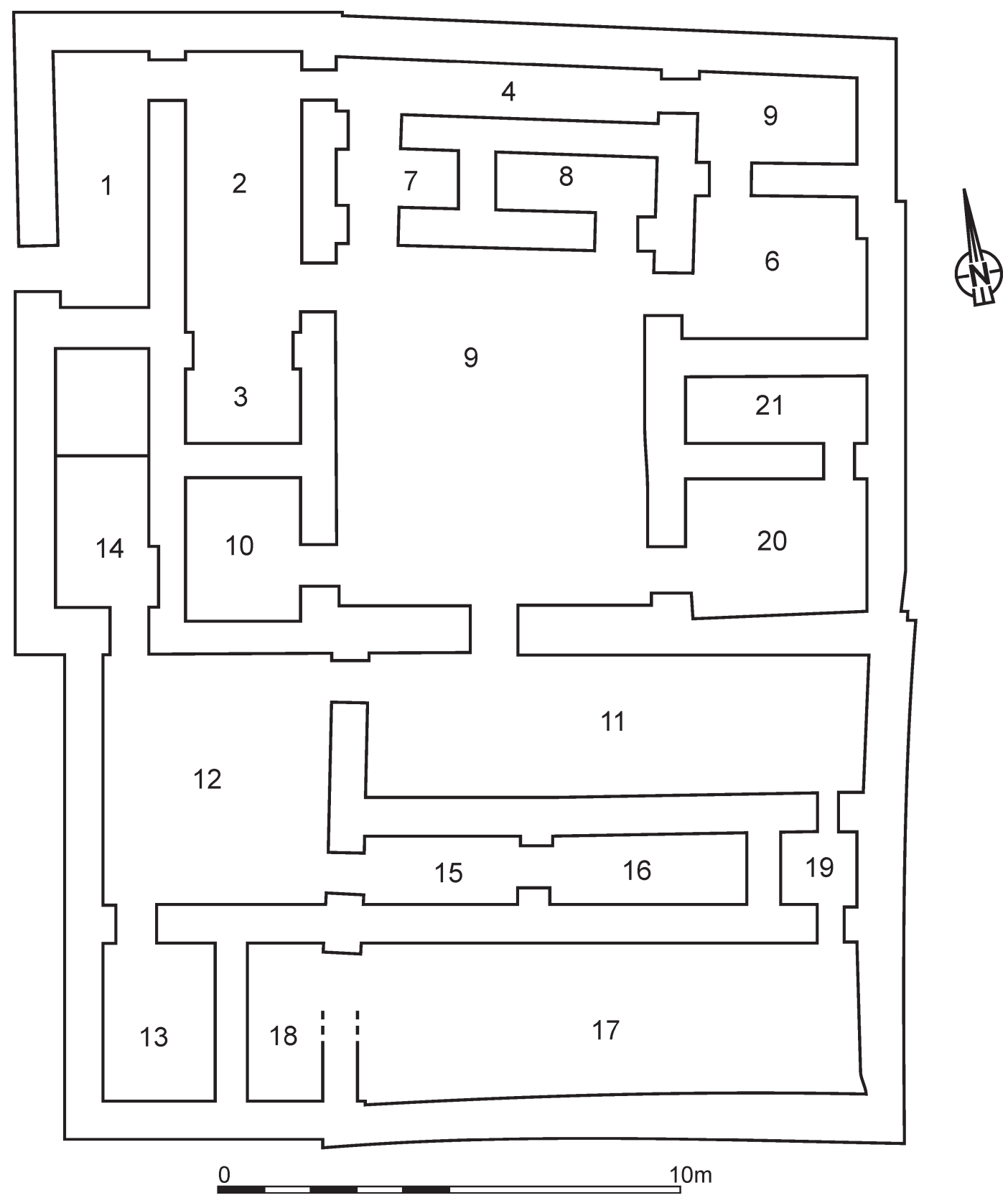

Plano da casa B 59 (segundo Calvet 2003)

(35) Em seu primeiro estudo do sítio, Gasche (1978) considerou várias das tumbas como intrusivas. Para uma síntese, ver Battini-Villard 1999: 257 ss. .

(36) De um ponto de vista arqueológico, o problema é de aceitar ou não a contemporaneidade entre a ocupação residencial do imóvel e a utilização das sepulturas do subsolo. Como notou Barrelet (1980), três hipóteses são possíveis: a presença concomitante de vivos e mortos de uma mesma família; a não concomitância (o que poderia corresponder a duas situações diversas: o abandono da 
REDE, M. Práticas funerárias, culto aos ancestrais e transmissão do patrimônio familiar na antiga Mesopotâmia. Rev. do Museu de Arqueologia e Etnologia, São Paulo, 14: 117-138, 2004.

O mesmo fenômeno repetia-se em outras cidades do sul sob o controle de Larsa nos anos que antecederam à conquista babilônica, por exemplo em Ur, onde a possibilidade de contextualizar no sítio a documentação epigráfica (devido ao fato de as escavações terem sido regulares) mostra o reforço do papel do primogênito nas práticas rituais da família. ${ }^{40} \mathrm{O}$ caso de Ur sugere, igualmente, que o controle exercido pelo primogênito não chegava a excluir totalmente os demais membros do grupo, mesmo em situações em que a partilha levava a uma nuclearização efetiva, com a partida dos filhos mais novos: nestes casos, uma série de rearranjos arquitetônicos na casa paterna podia garantir o acesso de todos os descendentes aos espaços sagrados dos ancestrais (Brusasco 1999/2000: 134). Como um exemplo a contrario, pode-se citar o caso de cidades em que os quarteirões residenciais são desprovidos de capelas domésticas, como Nippur, o que foi justamente interpretado como indício de uma ausência de associação entre o culto dos ancestrais e a transmissão do patrimônio entre as gerações. ${ }^{41}$ Tal fato, aliás, vai no mesmo sentido de uma ausência de tradição de sepultura intra muros em Nippur: os poucos casos observados parecem ser conseqüência de circunstâncias excepcionais, como invasões e epidemias, e não um costume recorrente. ${ }^{42}$

$O$ culto aos ancestrais exige não apenas espaços, mas também objetos sagrados. A posição privilegiada do primogênito é, assim, visível igualmente no acúmulo do mobiliário de caráter religioso. Quando da partilha dos filhos de Eštar-ilî, Iddin-Amurrum recebeu vários objetos que não têm equivalentes nas partes de seu irmão Iblutam: uma mesa-banšur, duas mesas de luxo e quatro pilões (TCL, 10,55:16'). Podemos pensar que se trata, ao menos em parte, de objetos ligados ao culto. A mesa-banšur pode ser equiparada à mesabanšur-zagula, uma espécie de bandeja de oferendas, particularmente associada a contextos rituais e que freqüentemente aparece na parte de herança dos primogênitos. ${ }^{43} \mathrm{~A}$ associação foi notada nos arquivos familiares de $\mathrm{Nippur}^{44}$ e estava presente também em $\mathrm{Ur}^{45}{ }^{45}$ sempre na época paleobabilônica. ${ }^{46}$ casa, transformada depois em depósito funerário, ou a instalação de sepulturas em uma casa já abandonada) e, enfim, uma terceira situação misturando as duas precedentes, mas em momentos diferentes. Nós poderíamos ajuntar uma variante da primeira situação: a ocupação da casa por uma família diferente daquela a que pertencem os despojos dos mortos aí presentes (com efeito, alguns dados da documentação epigráfica apontam neste sentido). No caso de Ur, em que a distinção entre os níveis da época de Larsa e da época cassita nem sempre fica clara a partir dos relatórios de escavação, Barrelet mostra-se muito reticente, evitando uma resposta definitiva acerca da relação entre casa e sepulturas. Por outro lado, retomando o problema, Luby (1990: 70) defendeu a hipótese de uma presença concomitante de vivos e mortos para o conjunto dos edifícios que apresentam tumbas intra muros; no mesmo sentido Brusasco 1999/2000: 71 ss. No sítio de Larsa, a presença simultânea está acima de qualquer dúvida.

(37) Medidas em Calvet 1997, anexo 1. Durante a campanha de 1989, uma terceira casa (B 54) foi parcialmente escavada mas o caráter incompleto do trabalho impede de estabelecer com certeza a presença de sepulcros. Estas duas mesmas características - dificuldade de acesso e grande dimensão dos cômodos sobre as caves - repetem-se também em Ur (Brusasco 1999/2000: 72 ss.). Para o caráter não fortuito da associação entre as caves funerárias e os maiores cômodos da residência, ver Luby 1990: 77.
(38) Poder-se-ia ver aqui uma contradição com o mecanismo de sorteio das partes, que tenderia a distribuir os lotes aleatoriamente entre os herdeiros. No entanto, é possível que os espaços sagrados fossem separados e reservados ao primogênito antes do sorteio, compondo a sua parte suplementar. De fato, nós estamos bastante mal informados sobre a questão e, nos arquivos da família Sanum, o sorteio jamais é mencionado explicitamente: no caso da partilha TCL, 11,200, linha 24, não é possível dizer com certeza se a expressão ina isqim (por porções) remete simplesmente aos lotes em divisão ou se ela evoca o sorteio. Charpin (1980: 176) reconhece que, nos dois únicos casos atestados na vizinha Kutalla (TS 29 e 44), "o procedimento de sorteio é evocado apenas (...) de modo muito alusivo".

(39) TCL, 11,174: 14: ha-la qá-du-um zag-gar-ra. O termo zag-gar-ra tem como equivalente acadiano aširtum (AhW, 1: 80 Heiligtum; CAD,A-2: 436: a special small room in a private house for cultic proposes). Prang (1977: 224) propõe uma associação com as capelas domésticas destinadas ao culto dos ancestrais. Para as dificuldades de interpretação, ver Van Der Toorn (1999: 142) que cita a literatura anterior. Para a capela familiar e seu papel na vida religiosa do grupo doméstico, ver em geral Van Der Toorn (1996b: $69 \mathrm{~s}$ ).

(40) Como Brusasco demostrou quanto à articulação entre a casa de 2 Church Lane e o contrato de partilha UET,5,112 a-b: os dados cadastrais sugerem que Sîntukulti, primogênito de Tâb-ilišu, recebeu a capela 
REDE, M. Práticas funerárias, culto aos ancestrais e transmissão do patrimônio familiar na antiga Mesopotâmia. Rev. do Museu de Arqueologia e Etnologia, São Paulo, 14: 117-138, 2004.

Tais fatos apontam para uma clara relação entre as práticas funerárias de Larsa, o culto aos mortos e as formas de diferenciação na partilha da herança. Na base desses procedimentos, encontramos um fenômeno mais geral: a apropriação do território implica a construção mental de uma ligação com os ancestrais em que o espaço controlado por cada grupo - que se separa, então, do território indiferenciado, não marcado por relações de posse material e simbólica - torna-se um elemento importante de uma ' geografia totêmica', o ponto de ligação entre os vivos e os mortos. ${ }^{47}$ A tradição mesopotâmica procedeu a uma unificação (jamais completa) entre a habitação dos primeiros e o lugar de repouso dos últimos, fazendo da casa um espaço simbólico de rememoração dos ancestrais. ${ }^{48}$ No que diz respeito à ocupação dos espaços, as implicações são evidentes, pois esta se apresenta como uma continuidade, como a manutenção de um laço genealógico entre a família e seu território doméstico: a referência ao passado serve para criar e reproduzir os direitos de acesso. ${ }^{49}$ A presença dos restos mortais dos ancestrais como fundamento de uma ancoragem legitimadora no passado manifestase, igualmente, no nível do poder palaciano: uma 'casa do ritual-kispum' (bît kispim) parece fazer parte da estrutura arquitetônica de alguns palácios e, no período neo-assírio, vários membros da dinastia reinante foram inumados no 'Palácio dos Pais', na residência real em Assur. ${ }^{50} \mathrm{Se}$ Assurbanipal, em seus Anais, ${ }^{51}$ vangloria-se de ter exposto os ossos dos ancestrais dos reis elamitas ao sol e os transferido para Assur, privando-os das oferendas e das libações, é justamente para enfatizar que a derrota leva a um total desenraizamento, espacial e temporal.

Certamente, as práticas de transmissão dos bens familiares não ficaram imunes a tais concepções. Não é por acaso que, muito cedo, alguns estudos aproximaram o termo sumério para herdeiro, ibila, e o culto familiar. Thureau-Dangin (1913: 97), por exemplo, propôs uma etimologia composta por $i$ (óleo) e bil (queimar), o que faria de ibila "aquele que faz queimar o óleo", num contexto ritual. De seu lado, Koschaker (1925: 114s.) aproveitou a mesma associação para reforçar sua idéia de que o culto dos ancestrais e a herança estariam ambos reservados exclusivamente aos descendentes do sexo masculino. Tanto a etimologia de Thureau-Dangin como a tese de Koschaker foram contestadas posteriormente, ${ }^{52}$ mas não se pode contestar a relação entre o processo de devolução dos bens e o culto aos ancestrais, mesmo

(45) Charpin (1980: $37 \mathrm{~s}$.) comentário a TS,5 com vários paralelos nos textos editados em UET,5; ver sobretudo as observações do autor sobre UET,5,109 em Charpin (1986: 107) e Brusasco (1999-2000: 129, n. 123).

(46) O fenômeno, no entanto, parece perdurar, como mostram as atestações em Emar e Nuzi, na segunda metade do segundo milênio.

(47) Para a construção desta paisagem fundada na referência aos ancestrais, ver Morphy (1997). Enquanto eu prefiro considerar este fenômeno no nível do grupo doméstico mais restrito, Götzelt (2002), tratando igualmente do período paleobabilônico, enfatiza a mesma ordem de idéias no quadro de uma sociedade segmentária de linhagens.

(48) Assegurar o repouso dos ancestrais que ainda 'habitavam' a casa e evitar, a todo preço, a sua fuga, com a conseqüente ruína do lar, era justamente a intenção de certas ações mágicas que se expressavam na forma de canções de ninar e encantamentos visando acalmar o choro das crianças, segundo a interpretação de Van Der Toorn (1999), que guarda certa distância em relação ao estudo de Farber (1989). Ver também Farber (1990). O problema da perturbação dos mortos foi tratado igualmente por Hallo (1993).

(49) Ver Gillespie (2000: 474 s.) e Peltenburg (1999: 428 s)

(50) Ver Cesari (2002:361s.). Eu me limito a evocar, aqui, as dimensões espaciais deste fenômeno de construção do 
REDE, M. Práticas funerárias, culto aos ancestrais e transmissão do patrimônio familiar na antiga Mesopotâmia. Rev. do Museu de Arqueologia e Etnologia, São Paulo, 14: 117-138, 2004.

se as modalidades de articulação nem sempre são claras. Em todo caso, alguns elementos de interpretação podem ser sugeridos, como faremos a seguir

\section{Transmissão material e herança imaterial}

Recentemente, no quadro dos estudos sobre as relações entre as gerações na Mesopotâmia, sugeriuse que o privilégio de primogenitura poderia corresponder a uma compensação material dos encargos e responsabilidades assumidas pelo filho mais velho no cuidado com os pais, sendo, assim, um mecanismo que visava garantir a subsistência das pessoas mais idosas, e improdutivas, da família (Westbrook 1998: 244 s.). No entanto, é difícil demonstrar cabalmente que uma lógica de compensação estivesse na origem da diferenciação entre os herdeiros. Mesmo se fosse este o caso, o aspecto puramente material dificilmente poderia explicar totalmente a cristalização da prática. De um lado, por diversas razões, o primogênito nem sempre era o responsável pelos genitores economicamente inativos $\mathrm{e}$, a menos que se dissocie a figura do herdeiro privilegiado na partilha daquela do filho primogênito, o que me parece pouquíssimo provável, uma tal situação degeneraria fatalmente em um conflito entre o destinatário 'natural' da parte suplementar e um cadete que, eventualmente, tivesse cuidado dos pais na velhice. Ora, uma tal tensão não encontra eco em nossas fontes, o que sugere que a manutenção dos membros da geração anterior não justificaria a reivindicação de um privilégio sucessório. ${ }^{53}$ Por outro lado, normalmente, a partilha era feita post-mortem e o efeito prático de uma distribuição desigual dos bens sobre os cuidados dispensados aos pais seria restrito: se a parte suplementar tivesse realmente tal finalidade, nós esperaríamos uma maior freqüência das antecipações de herança ou, ao menos, da parte suplementar, por intermédio de testamentos; no entanto, estes são muito raros. ${ }^{54}$

Parece, então, que o privilégio de primogenitura, com sua parte suplementar na partilha do patrimônio, tem uma outra razão de ser e que sua relação com o culto dos ancestrais deve situar-se mais provavelmente em um nível simbólico.

De um modo geral, a primogenitura foi uma estratégia do grupo doméstico para fazer face à fragmentação do patrimônio implicada pelas regras de partilha não excludentes que prevaleciam na Mesopotâmia. A diferenciação entre os irmãos germanos exigia, no entanto, uma legitimação que, sozinha, a ordem de nascimento não poderia oferecer. O controle dos espaços sagrados da família, o monopólio dos objetos rituais, o desempenho de um papel cerimonial mais importante do que o dos demais, enfim, a criação de um laço privilegiado com os ancestrais serviram para justificar e consolidar, no nível das representações simbólicas, a posição diferenciada do primogênito.

Deste ponto de vista, a adequada compreensão do processo de repartição dos bens materiais não pode se dar a não ser em conexão com a herança imaterial Certos autores, entretanto, negaram a existência de uma caráter ancestral que comporta, todavia, outros aspectos, como por exemplo o estabelecimento de genealogias, reais ou ficcionais; para as genealogias da dinastia real, ver Finkelstein (1966); por outro lado, Wilson (1977: $71 \mathrm{s.}$ ) pretendeu que as genealogias dinásticas mesopotâmicas tivessem um peso reduzido na legitimação do poder real, o que não parece encontrar sustentação nos dados disponíveis: além do trabalho de Cesari, citado acima, ver Michalowski (1983) e, sobretudo, Jonker (1995).

(51) Texto em Luckenbill (1927: 310).

(52) Para a etimologia de 'ibila', ver Kraus (1969b: 35 ss.). Para a tese de Koschaker, ver Driver e Miles (1952: 329 ss.) e Klíma (1940 e 1950). Para uma síntese do problema, ver Skaist (1980: 123 ss.). A participação das mulheres como oficiantes nos rituais mortuários, mesmo excepcional, é atestada (Van Der Toorn 1994: 46 e 1996a: 49; para o caso de uma sacerdotisa-nadîtum, ver Harris 1964: 122). (53) Ainda mais porque tal hipótese implicaria deserdar, ao menos parcialmente, o primogênito, o que é um procedi- mento bastante limitado pelas legislações mesopotâmicas, como reconhece o próprio Westbrook (1998: 244).

(54) É preciso distinguir tal situação da concessão de um benefício a um escravo ou a um filho adotado em troca dos cuidados dispensados ao senhor ou aos pais adotantes durante a velhice (ver Greenfield 2001: $913 \mathrm{~s}$; Stol 1998: 100 s. e Veenhof 1982: 359 ss.). Os casos de adoção, aliás comuns entre sacerdotisas impedidas de procriar, ou de manumissão de escravos dizem respeito a mecanismos individualizados de auto-proteção, que são acionados na ausência de uma rede de seguridade pública ou de solidariedade familiar ou comunitária, mas não alteram substancialmente o sistema de herança, pois nenhuma distinção é feita entre os germanos e nenhuma primogenitura deriva de tais dispositivos. Na verdade, os raros casos nos quais uma compensação sucessória pode ser estabelecida em função de cuidados concedidos aos pais mostram claramente uma disposição testamental excepcional, contra a regra costumeira. 
REDE, M. Práticas funerárias, culto aos ancestrais e transmissão do patrimônio familiar na antiga Mesopotâmia. Rev. do Museu de Arqueologia e Etnologia, São Paulo, 14: 117-138, 2004.

relação entre o culto aos ancestrais e a herança na Mesopotâmia. É o caso de Miranda Bayliss (1973), cuja argumentação merece ser analisada em detalhe. Partindo de um modelo fundado na comparação antropológica, Bayliss enfatizou o caráter apaziguador do culto mortuário mesopotâmico, que ela considerou como uma resposta à tensão entre as gerações, presente entre os vivos e que se prolongava na relação com os ancestrais. Por outro lado, a autora reconhece apenas um papel reduzido do culto aos ancestrais na formação da identidade do grupo familiare, sobretudo, nega qualquer laço com o processo de herança ou com uma posição especial do primogênito. Arazão principal desta negação repousa sobre um contraste estabelecido pela autora entre a sociedade mesopotâmica e um modelo africano: neste último, a profundidade da sucessão, em um quadro de linhagens, contribui para transformar a remissão aos ancestrais em um dado fundamental da dinâmica de transmissão de bens, posições e poderes. Entre os mesopotâmios, ao contrário, a ausência de uma organização em linhagens (mesmo se a autora nos lembra da existência de traços residuais em certos reinos amorritas do início do segundo milênio) teria implicado uma separação entre a sucessão e o culto aos ancestrais.

Mas seria necessário estabelecer uma oposição tão drástica entre os dois modelos? Se é este o caso, onde deveria passar a linha de fronteira?

A resposta não é, em todo caso, evidente. Por exemplo, mesmo não compartilhando as conclusões de Bayliss, eu creio que a base de seu raciocínio sobre a tensão entre gerações é correta. Skaist (1980) manifestou uma opinião diferente: para ele, na Mesopotâmia, a relação entre as gerações seria desprovida de caráter conflituoso e os contatos rituais entre os vivos e os mortos desenvolver-se-iam em um quadro positivo e propiciatório, havendo poucos momentos de fricção. Nesta visão, por conseqüência, a função principal dos cultos mortuários seria assegurar a boa relação com as forças do além e a relação entre o culto aos ancestrais e a sucessão darse-ia não mais em um contexto de tensão, mas de cooperação benfazeja entre as gerações. No entanto, e creio que a maior parte dos autores que estudaram o tema concordaria comigo, o conjunto dos dados à nossa disposição (a própria natureza do ritual kispum; o conteúdo das preces e encantamentos; as narrativas mitológicas que informam sobre a ideologia da morte etc.) permite estabelecer, apesar de uma situação bastante complexa, o predomínio de uma visão pessimista da morte e de um conflito inerente às relações entre os vivos e os mortos. ${ }^{55}$ Parece-me, então, que não seja possível negar tal tensão (como o faz Skaist), nem a considerar inócua, situando-a em um nível inexistente ou residual na sociedade Mesopotâmica (a linhagem de Bayliss). Com efeito, é no interior do grupo doméstico que os conflitos devem ser observados. Ameu ver, a verdadeira distinção entre o caso mesopotâmico e o modelo de linhagem africano não se situa na ausência de tensão, mas na forma social pela qual ela se expressa. É a própria noção de ancestral que deve, portanto, ser redefinida a fim de evitar comparações deformadoras: enquanto que, na África, ela será forçosamente mais larga e mais profunda, devido ao sistema de linhagens, para os grupos urbanos de Larsa ou Babilônia, os seus limites são dados, sobretudo, pelas relações de filiação, inclusive excluindo as alianças por casamento do campo da ancestralidade. ${ }^{56}$ Uma outra diferença situa-se no modo como o culto aos ancestrais era, na Mesopotâmia, fundamentalmente sedentarizado, de onde todos os problemas no âmbito da transmissão dos imóveis vistos até aqui. Se a idéia de Mirko Novák (2000) é correta, como penso, a tendência a conservar uma proximidade geográfica com os mortos, sepultando-os na própria residência familiar, exprime não o desejo de proximidade, como se poderia acreditar em uma primeira abordagem, mas a necessidade psicológica de criar e manter uma distância controlada entre os vivos e os mortos (ou melhor, seus 'espíritos': gidim em sumério, etemmum em acadiano): garantir a passagem definitiva para o mundo subterrâneo e preservar as condições de repouso através da correta realização dos cultos mortuários é, antes de mais nada, uma forma de proteção de todos os membros do grupo face às forças negativas personificadas pelos defuntos. Sepultá-los no subsolo da casa é, paradoxalmente, uma maneira de mantê-los longe do mundo dos vivos. Assim, a responsabilidade simbólica agregada à primogenitura faz do fillho mais velho uma garantia do bem-estar da família, contra seus próprios ancestrais.

(55) Alguns trabalhos sobre a questão: Heidel (1949); Bottéro (1980 e 1983); Penglase (1996).

(56) Ver Schmidt (1996: 10) e Bayliss (1973: 119). Em contraste, o kispum dos reis beduínos do norte mesopotâmico integrava os aliados e mesmo os clientes (Durand 2000/1: 695 e Lafont 1999: 69), o que mostra, justamente, a distância entre as unidades domésticas que formam a base da sociedade da Baixa Mesopotâmia, de que tratamos aqui, e as realidades tribais amorritas da Síria. 
REDE, M. Práticas funerárias, culto aos ancestrais e transmissão do patrimônio familiar na antiga Mesopotâmia. Rev. do Museu de Arqueologia e Etnologia, São Paulo, 14: 117-138, 2004.

REDE, M. Funerary practices, ancestors cult, and the transmission of family estate in ancient Mesopotamia. Rev. do Museu de Arqueologia e Etnologia, São Paulo, 14: 117-138, 2004.

ABSTRACT: The aim of this article is to establish relations between two phenomena: from one side, the transmission of the family estate and, from the other, the funerary practices, in particular in contexts of inhumations in the house underground. One can see that the need of securing the cult of ancestors by means of funerary rites had an important role in the process of material and symbolic inheritance of the domestic group in the Babylonian region, and was decisive to distinguish the position of the first born son from that of the other heirs.

UNITERMS: Estate - Inheritance - Funerary practices - Mesopotamia - Larsa Cult for the ancestors.

\begin{tabular}{|c|c|}
\hline \multicolumn{2}{|c|}{ Abreviações } \\
\hline AHw: W. Von Soden - Akkadisches Handwörterbuch. & PSBA: Proceedings of the Society of Biblical \\
\hline 3 volumes. Wiesbaden, 1965-1981. & Archaeology (Londres). \\
\hline AO: Antiquités Orientales (Tabletes do Museu do & RA: Revue d'Assyriologie et d'Archéologie \\
\hline Louvre). & Orientale (Paris). \\
\hline ARM: Archives Royales de Mari (Paris). & RGTC: Répertoire Géographique des Textes \\
\hline CAD: The Assyrian Dictionary of the Oriental & Cunéiformes (Tübingen). \\
\hline Institute of the University of Chicago. Chicago, & RS: Rîm-Sîn \\
\hline 1958 ss. & Si: Samsu-iluna \\
\hline Ha:Hammu-rabi & TCL: Textes Cunéiformes du Louvre (Paris). \\
\hline HG: Hammurapi Gesetz & TS: Textes de Tell Sifr (Kutalla). \\
\hline NBC: Tablete da Nies Babylonian Collection (New & UET: Ur Excavation Texts (London, Philadelphia) \\
\hline Haven). & WS: Warad-Sîn \\
\hline Ni: Tablete de Nippur - Museu de Istanbul. & YBC: Tablete da Yale Babylonian Collection (Ner \\
\hline OECT: Oxford Editions of Cuneiform Texts & Haven). \\
\hline (Oxford). & YOS: Yale Oriental Series (New Haven). \\
\hline
\end{tabular}

\section{Referências bibliográficas}

AKKERMANS, P. E ROSSMEISL, I.

1990 Excavations at Tell Sabi Abyad, Northers Syria: a regional centre of the Assyrian frontier. Akkadica, 66: 13-60.

ALGAZE, G

1983/4 Private houses and graves at Ingharra, a reconsideration. Mesopotamia, 18/19: 135155 .

AUGUSTINS, G

1989 Comment se perpétuer? Devenir de lignées et destins des patrimoines dans les paysanneries européennes. Nanterre, Société d'Ethnologie.
BACHELOT, L. ETALII

2001 Tell Shioukh Faouqâni: campagne 2000 Orient Express, 1: 9-15.

BAKER, $\mathrm{H}$.

1996 Neo-Babylonian burials revisited. S. Campbell e A. Green (Eds.) The archaeology of death in the ancient Near East (Oxbow Monograph, 51).

BARRELET, M.T.

1980 Les pratiques funéraires de l'Iraq ancien et 1'archéologie: état de la question et essai de prospective. Akkadica, 16: 2-27. 
REDE, M. Práticas funerárias, culto aos ancestrais e transmissão do patrimônio familiar na antiga Mesopotâmia. Rev. do Museu de Arqueologia e Etnologia, São Paulo, 14: 117-138, 2004.

\section{BATTINI-VILLARD, L}

1999 L'espace domestique en Mésopotamie de la III dynastie d'Ur à l'époque paléo-babylonienne, 2 volumes (BAR International Séries, 767).

BAYLISS, $\mathrm{M}$. Oxford, British Archaeological Reports

1973 The cult of dead kin in Assyria and Babylonia. Iraq, 35: 115-125.

BOTTÉRO, J.

1980 La mythologie de la mort en Mésopotamie ancienne. B. Alster (Ed.) Death in Mesopotamia $\left(26^{\mathrm{e}}\right.$ Rencontre Assyriologique Internationale / Copenhagen Studies in Assyriology, 8). Copenhagen, Akademisk Forlag: 25-52.

1983 Les morts et l'au-delà dans le rituels en accadien contre l'action des 'revenants' Zeitschrift für Assyriologie, 73: 153-203.

BOURDIEU, P

1972 Les stratégies matrimoniales dans le système de reproduction. Annales, 27: 1105-1127.

BRUSASCO, P.

1999-2000 Family archives and the social use of space in Old Babylonian houses at Ur. Mesopotamia, 34/35: 1-173

BUTZ, K.

1981 Eine altbabylonisch Erbteilungsurkunde aus $\mathrm{Ur}$, angeblich aus Larsa. Oriens Antiquus, 20: 195-201

CALVET, Y.

1993 Maisons privées paléo-babyloniennes à Larsa. Remarques d'architecture. K. R. Veenhof (Ed.) Houses and households in ancient Mesopotamia (40 Rencontre Assyriologique Internationale). Leiden, Nederlands Historisch-Archaeologisch Intstituut te Istanbul: 197-209.

1994 Les grandes résidences paléo-Babyloniennes de Larsa. H. Gasche ; M. Tanret ; C. Janssen; A. Degrave (Eds.) Cinquante-deux réflexions sur le Proche-Orient ancien (Mélanges Léon De Meyer / Mesopotamian History and Environment, Occasional Puvlications, 2). Leuven: Peeters: 215-228.

1997 La place de Larsa dans l'architecture domestique mésopotamienne du II millénaire. Thèse de doctorat, EPHE, Paris.

2003 Bâtiments paléobabyloniens à Larsa. J.-L. Huot (Ed.) Larsa. Travaux de 1987 et 1989. (Bibliothèque Archéologique et Historique, 165). Beyrouth, Institut Français d'Archéologie du Proche-Orient: 143-297.

CASTEL, C.

1992 Habitat urbain Néo-Assyrien et NéoBabylonien. De l'espace bâti à l'espace vécu. Volume 2 (Bibliothèque Archéologique et Historique, 143). Paris: Geuthner.

CASTEL, C.; CHARPIN, D.

1997 Les maisons mésopotamiennes. Essai de dialogue entre archéologue et épigraphiste. C. Castel; M. Al-Maqdissi; F. Villeneuve (Eds.)
Les maisons dans la Syrie antique du III millénaire aux débuts de l'Islam. Pratiques et représentations de l'espace domestique. Beyrouth, IFAPO: 243-253

CESARI, C. DE

2002 Graves as public space? Some questions about possible «public» aspects of graves and cemeteries in ancient Mesopotamia. Altorientalische Forschungen, 29: 355-366

CHARPIN, D.

1980 Archives Familiales et propriété privé en Babylonie ancienne: étude des documents de Tell Sifr (Hautes Etudes Orientales, 12).

Genève: Librairie Droz.

1986 Le clergé d'Ur au siècle d'Hammurabi (XIX XVIII siècles av. J.-C.). Genève: Droz.

1996 Maisons et maisonnées en Babylonie ancienne de Sippar à Ur: remarques sur les grandes demeures des notables paléobabyoniens. K. R. Veenhof (Ed.) Houses and households in ancient Mesopotamia. (40 Rencontre Assyriologique International). Leiden, Nederlands Historisch-Archaeologisch Instituut te Istanbul: 221-228.

ÇIG, M.; KIZILYAY, H.; KRAUS, F.R.

1952 Altbabylonische Rechtsurkunden aus Nippur. Istanbul, Milli Eœitim Basimevi

\section{CRAWFORD, H.E.W.}

1977 The architecture of Iraq in the third millennium B.C. (Mesopotamia Copenhagen Studies in Assyriology, 5). Copenhagen: Akademisk Forlag.

CUQ, E.

1929 Etudes sur le droit Babylonien, les lois Assyriennes et les lois Hittites. Paris: Geuthner.

DALLEY, S.; AL-RAWI, F

2000 Old Babylonian texts from private houses at Abu Habbah, ancient Sippir. (E.DUB-BA-A, 7), Baghdad.

DÉSVEAUX, E

1994 L'alliance et la filiation comme maîtrise de l'espace, le territoire comme gouvernement des hommes. F. Héritier-Augé ; E. CopetRougier (Eds.) Les complexités de l'alliance. Volume 4: Economie, politique et fondements symboliques. Paris, Editions des Archives Contemporaines: 47-71.

DOMBRADI, E.

1996 Die Darstellung des Rechtsaustrags in den altbabylonischen Prozessurkunden.

(Freiburger altorientalische Studien, 20,1 e 2). Stuttgart: Franz Steiner Verlag.

DRIVER, G; MILES, J.

1952 Babylonian Laws. Volume 1: Legal Commentary. Oxford: Clarendon Press.

DURAND, J.- M

1989 Tombes familiales et culte des ancêtres à Emar. Nouvelles Assyriologiques Brèves et Utilitaires, 4: 85-88. 
REDE, M. Práticas funerárias, culto aos ancestrais e transmissão do patrimônio familiar na antiga Mesopotâmia. Rev. do Museu de Arqueologia e Etnologia, São Paulo, 14: 117-138, 2004.

2000 Documents épistolaires du palais de Mari. Volume 3 (Littératures Anciennes du ProcheOrient, 18). Paris: Cerf.

2000-2001 Résumé des cours et travaux Assyriologie. Annuaire du Collège de France. Paris: 693-705.

FARBER, W.

1989 Schlaf, Kindchen, schlaf! Mesopotamische Baby-Beschwörungen und Rituale. (Mesopotamian Civilizations, 2). Winona Lake: Eisenbrauns.

1990 Magic at the cradle. Babylonian and Assyrian lullabies. Anthropos, 85: 139-148.

FEDELE, F.

1994 Religioni della preistoria. G. Filoramo (Ed.) Storia delle religioni. Volume 1: Le religioni antiche. Roma-Bari, Laterza: 15-57.

FINKELSTEIN, J.J.

1966 The genealogy of the Hammurapi dynasty Journal of Cuneiform Studies, 20: 95-118.

FOREST, J. D

1983 Les pratiques funéraires en Mésopotamie du $5^{e}$ millénaire au début du $3^{e}$, étude de cas. Paris: ERC.

GASCHE, H.

1978 Le sondage A: l'ensemble I. L. de Meyer (Ed.) Tell ed-Dêr II. Progress reports. Leuven, Peeters: 57-131.

GENOUILLAC, H. DE

1936 Fouilles de Telloh, Volume 2: Epoques d'Ur III Dynastie et de Larsa. Paris: Geuthner.

GILLESPIE, S.D.

2000 Rethinking ancient Maya social organization: replacing 'lineage' with 'house'. American Anthropologist, 102: 467-484

GODDEERIS, A.

2002 Economy and society in northern Babylonia in the early old Babylonian period (ca. 2000 1800 BC). (Orientalia Lovaniensia Analecta, 109). Leuven: Peeters.

GÖTZELT, T.

2002 Descent, private and public: Social environments in early Mesopotamia (Old Babylonian period). Altorientalische Forschungen, 29: 339-354

GOODY, J.

1962 Death, property and the ancestors. A study of the mortuary customs of the LoDagaa of West Africa. California: Standford University Press.

GREENFIELD, J.C.

2001 Adi balÿu: care for the elderly and its rewards S. M. Paul; M.E. Stone; A. Pinnick (Eds.) ' $A l$ kanfei yonah. Collected studies of Jonas $C$. Greenfield on semitic philology. Volume 2. Leiden, Brill: 912-919.

HALLER, A.

1954 Die Gräber und Grüfte von Assur. (Wissenschaftliche Verõffentlichung der Deutschen Orient-Gesellschaft, 65). Berlin: Verlag Gebr. Mann.
HALLO, W.W.

1993 Disturbing the dead. M. Brettler; M. Fishbane (Eds.) Minhah le-Nahum. Biblical and others studies presented to Nahum M. Sarna in honour of his $70^{\text {th }}$ birthday. Sheffield, JSOT Press: 183-192.

2002 A model court case concerning inheritance. T. Abusch (Ed.) Riches hidden in secret places. (Mélanges Thorkild Jacobsen). Winona Lake, Eisenbrauns: 141-152.

HARRIS, R.

1964 The nadîtu woman. R.D. Biggs et alii Studies presented to A. Leo Oppenheim. Chicago, The University of Chicago Press: 106-135.

1975 Ancient Sippar. A demographic study of an Old-Babylonian city (1894-1595 B.C.). (Publications de l'Institut Historique et Archéologique de Stamboul, 36). Istanbul, Nederlands Historisch-Archaeologisch Instituut te istanbul.

1976 On kinship and inheritance in Old Babylonian Sippar. Iraq, 38 (129-132).

HEIDEL, A.

1949 Death and the Afterlife. A. Heidel The Gilgamesh epic and Old Testament parallels. Chicago, The University of Chicago Press: 137-223.

HEIMPEL, W.

1997 Disposition of households of officials in Ur III et Mari. Acta Sumerologica, 19: 63-82.

HENRICKSON, E.F.

1981 Non-religious residential settlement patterning in the Late Early Dynastic of Diyala region. Mesopotamia, 16: 73-79.

HIRSCHHORN, M.; BERTHELOT, J.M.

1996 Mobilités et ancrages. Vers un nouveau mode de spatialisation? Paris: L'Harmattan.

HOFMAN, J.M.

1997 La relation habitat sépulture à l'époque paléo-babylonienne. Volume 1. Mémoire de DEA, Université de Paris 1 PanthéonSorbonne. Paris.

HUNTER, GR

1930 The Sayce and H. Weld collection in the Ashmolean Museum. Sumerian contracts from Nippur. (Oxford Editions of Cuneiform Texts, 8). Oxford: Oxford University Press.

HUOT, J.-L.

1991a Les travaux français à Tell el 'Oueili et Larsa. Un bilan provisoire. Akkadica, 73: 1-32

$1991 b$ Tell es-Sinkarah Larsa (Iraq). Orient Express, $1: 3$.

1991c Larsa, de la théorie au chantier. M. Baud (Ed.) Cités disparues. Paris: 103-114.

2003 Larsa: Travaux de 1987 et 1989. (Bibliothèque Archéologique et Historique, 165). Beiruth, Institut Français d'Archéologie du ProcheOrient.

JEAN-MARIE, M.

1990 Les tombeaux en pierres de Mari. Mari Annales de Recherches Interdisciplinaires, 6: 303-336. 
REDE, M. Práticas funerárias, culto aos ancestrais e transmissão do patrimônio familiar na antiga Mesopotâmia. Rev. do Museu de Arqueologia e Etnologia, São Paulo, 14: 117-138, 2004.

\author{
JONKER, G \\ 1995 The topography of remembrance. The dead, \\ tradition and collective memory in \\ Mesopotamia. Leiden: E.J. Brill. \\ KLIMA, J. \\ 1940 Untersuchungen zum altbabylonischen \\ Erbrecht (Monographien des Archiv \\ Orientální, 8). Prag, Orientalisches Institut. \\ 1950 La position successorale de la fille dans la \\ Babylonie ancienne. Archiv Orientální, 18: \\ 150-186.

\section{KOPPEN, F. VAN} \\ 2002 Seized by royal order. The households of \\ Sammêtar and others magnates at Mari. D. \\ Charpin; J.-M. Durand (Eds.) Récueil \\ d'études à la mémoire d'André Parrot. \\ (Florilegium Marianum, 6/ Mémoires de \\ NABU, 7). Paris, SEPOA: 289-372 \\ KOSCHAKER, $\mathrm{P}$ \\ 1925 Erbrecht (Vorderasien). Reallexikon der \\ Vorgeschichte. Volume 3. Berlin, Walter de \\ Gruyter et Co.: 114-119. \\ KRAUS, F.R. \\ 1951 Nippur und Isin nach altbabylonischen \\ Rechtsurkunden. Journal of Cuneiform \\ Studies, 3: 1-228.
}

1954 Neu Rechtsurkunden der altbabylonischen Zeit. Bemerkungen zu Ur Excavations Texts 5. Die Welt des Orients, 2: 120-136.

1969a Von altmesopotamischen Erbrecht. J. Brugman et alii Essays on oriental laws of succession (Studia et Documenta ad Iura Orientis Antiqui Pertinentia, 9). Leiden: E.J. Brill.

1969b Erbrechtliche Terminologie im alten Mesopotamien. J. Brugman et alii Essays on oriental laws of succession (Studia et Documenta ad Iura Orientis Antiqui Pertinentia, 9). Leiden: E.J. Brill.

\section{LAFONT, B.}

1999 Sacrifices et rituels à Mari et dans la Bible. Revue d'Assyriologie et Archéologie Orientale, 93: 57-77.

2001 Fortunes, héritages et patrimoines dans la haute histoire mésopotamienne. À propos de quelques inventaires de bien mobiliers. C. Breniquet; Ch. Kepinski (Eds.) Études Mésopotamiens (mélanges J.-L. Huot). Paris, ERC: 295-313.

LAFONT, S.

1992 Les partages successoraux paléobabyloniens. P. Benoit; K. Chemla; J. Ritter (Eds.) Histoires de fractions, fractions d'histoire. Basel, Birkhauser Verlag: 107-114.

LANERI, N.

1999 Intramural tombs. A funerary tradition of the Middle Euphrates valley during the III $^{\text {rd }}$ millennium BC. Anatolica, 25: 221-241.

LEEMANS, W.F.

1950 The Old-Babylonian merchant. His business and his social position (Studia et Documenta ad Iura Orientis Antiqui Pertinentia, 3).

Leiden: E.J. Brill.

1955 The Old-Babylonian business documents from Ur. Bibliotheca Orientalis, 12: 112-122.

LE ROY LADURIE, E.

2002 Histoire des paysans français. De la peste noire à la Révolution. Paris: Seuil.

LIVERANI, M.

1984 Land tenure and inheritance in ancient Near East: the interaction between 'palace' and 'family' sectors. T. Khalidi (Ed.) Land tenure and social transformation in the Middle East. Beirut, American University of Beirut: 33-44.

LUBY, E.M.

1990 Social variation in ancient Mesopotamia: an architectural and mortuary analysis of Ur in the early second millennium B.C. New York, State University of New York. Unpublished $\mathrm{Ph}$. D.

LUCKENBILL, D.D.

1927 Ancient records of Assyria and Babylonia. 2 volumes. Chicago: Chicago University Press.

MATOUŠ, L.

1949 Les contrats de partage de Larsa provenant des archives d'Iddin-Amurrum. Archiv Orientální, 17: 142-175.

1950 Les contrats de vente d'immeubles provenant de Larsa. Archiv Orientální, 18: 11-67.

MERPERT, N.I.; MUNCHAEV, R.M.; BADER, N.O.

1981 Investigation of the Soviet expediction in northern Iraq, 1976. Sumer, 37: 22-54.

MICHALOWSKI, P

1983 History as charter: some observations on the Sumerian King List. Journal of the American Oriental Society, 103: 237-248.

MILES, J

1954 Some remarks on the origins of testacy, with some references to the Old-Babylonian laws. Revue Internationale de Droits de l'Antiquité, 1: 119-124.

MOOREY, P.R.S

1980 Cemeteries of the first millennium B.C. at Deve Hüyük, near Carchemish, salvaged by T.E. Lawrence and C.L. Wooley in 1913. (BAR International Series, 87). Oxford.

MORMONT, M

1996 L'environnement entre localité et globalité. M. Hirschhorn; J.M. Berthelot (Eds.) Mobilités et ancrages. Vers un nouveau mode de spatialisation? Paris, L'Harmattan: 57-77.

MORPHY, H.

1997 Landscape and the reproduction of the ancestral past. E. Hirsch; M. O'Hanlon (Eds.) The anthropology of landscape. Perspectives on place and space. Oxford, Clarendon Press: 184-209.

MÜLLER, V.

1940 Types of Mesopotamian Houses. Journal of American Oriental Society, 60: 151-180. 
REDE, M. Práticas funerárias, culto aos ancestrais e transmissão do patrimônio familiar na antiga Mesopotâmia. Rev. do Museu de Arqueologia e Etnologia, São Paulo, 14: 117-138, 2004.

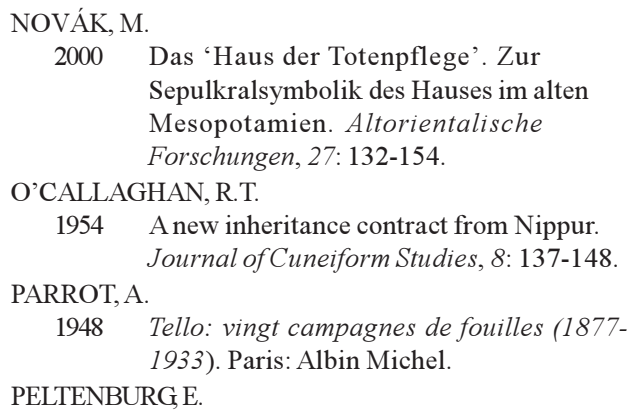

1999 The living and the ancestors: Early Bronze Age mortuary practices at Jerablus Tahtani. G. del Olmo Lete; J.-L. Montero Fenollós (Eds.) Archaeology of the Upper Syrian Euphrates. The Tishrin Dam area (Aula Orientalis Supplementa, 15). Barcelona: Ausa.

PELTENBURG, E. et alii

1996 Jerablus-Tahtani, Syria, 1995: preliminary report. Levant, 27: 1-25.

PENGLASE, C

1996 Some concepts of afterlife in Mesopotamia and Greece. S. Campbell; A. Green (Eds.) The archaeology of death in the ancient Near East (Oxbow Monograph, 51).

POLLARD, J.

1999 'These places have their moments': thoughts on settlement practices in the British Neolithic. J. Brück; M. Goodman (Eds.) Making places in the prehistoric world. Themes in settlement archaeology. Cambridge, UCL Press: 76-93.

PRANG E.

1976 Das Archiv des Imgûa. Zeitschrift für Assyriologie, 66: 1-44.

1977 Das Archiv des Bitûa. Zeitschrift für Assyriologie, 67: 217-234.

1980 Sonderbestimmungen in altbabylonischen Erbteilungsurkunden aus Nippur. Zeitschrift für Assyriologie, 70: 36-51.

REMY, J

1996 Mobilités et ancrages: vers une autre définition de la ville. M. Hirschhorn; J.M. Berthelot (Eds.) Mobilités et ancrages. Vers un nouveau mode de spatialisation? Paris, L'Harmattan: 135-153.

\section{REUTHER, O.}

1926 Die Innenstadt von Babylon (Merkes) (Wissenschaftliche Verõffentlichung der Deutschen Orient-Gesellschaft, 47). Leipzig Hinrischs'sche Buchhandlung.

RIIS, P.J.

1948 Hama, fouilles et recherches de la Fondation Calsberg (1931-1938). Les cimetières à crémation. Kobenhavn: Nordisk Forlag.

ROBERT, M

1995 L'archictecture domestique en Mésopotamie durant le $3^{\text {ème }}$ Millénaire av. J.-C. Mémoire de Maîtrise. Université Laval.

SCHLOEN, J.D.

2001 The house of the father as fact and symbol. Patrimonialism in Ugarit and the ancient Near East. Winona Lake: Eisenbrauns.

\section{SCHMIDT, B.B.}

1996 The extra-biblical textual evidence from SyriaPalestine: the late third to early second millennia B.C.E. B.B. Schmidt Israel's beneficent dead. Ancestor cult and necromancy in ancient Israelite religion and tradition. Winona Lake, Eisenbrauns: 14-46.

SKAIST, A

1974 Inheritance laws and their social background Journal of the American Oriental Society, 95: 242-247.

1980 The ancestors cult and succession in Mesopotamia. B. Alster (Ed.) Death in Mesopotamia (26 Rencontre Assyriologique Internationale / Copenhagen Studies in Assyriology, 8). Copenhagen, Akademisk Forlag: 123-128.

STOL, M

1998 The care of elderly in Mesopotamia in the old Babylonian period. M. Stol; S.P. Vleeming (Eds.) The care of the elderly in the ancient Near East. (Studies in the History and Culture of the Ancient Near East, 14). Leiden, E.J. Brill: 59-117.

STONE, E.C.

1987 Nippur Neighbourhoods (Studies in Ancient Oriental Civilization, 44). Chicago: The Oriental Institute of the University of Chicago.

1991 Adoption in old Babylonian Nippur. E.C. Stone; D.I. Owen Adoption in old Babylonian Nippur and the archive of Mannum-mešu-liu. Winona Lake, Eisenbrauns: 1-33.

1996 Houses, households and neighborhoods in the old Babylonian period: the role of extended families. K.R. Veenhof (Ed.) Houses and households in ancient Mesopotamia $\left(40^{\mathrm{e}}\right.$ Rencontre Assyriologique Internationale). Leiden, Nederlands Historisch-Archaeologisch Intstituut te Istanbul: 229-235.

STROMMENGER, E.

1957-1971 Grab. Reallexikon der Assyriologie, Volume 3. Berlin, Walter de Gruyter: 581-593.

THUREAU-DANGIN, F.

1913 Notes assyriologiques, 21: ablu-ibila. Revue d'Assyriologie et d'Archéologie Orientale, 10: 93-97.

TSUKIMOTO, A.

1980 Aspekte von kispu(m) als Totenbeigabe. B. Alster (Ed.) Death in Mesopotamia (26 Rencontre Assyriologique Internationale / Copenhagen Studies in Assyriology, 8). Copenhagen, Akademisk Forlag: 129-138.

1985 Untersuchungen zur Totenpflege (kispum) im 
REDE, M. Práticas funerárias, culto aos ancestrais e transmissão do patrimônio familiar na antiga Mesopotâmia. Rev. do Museu de Arqueologia e Etnologia, São Paulo, 14: 117-138, 2004.

\author{
alten Mesopotamien. (Alter Orient und Altes \\ Testament, 216). Neukirchen: Verlag Butzon \\ und Bercker Kevelaer. \\ VAN DE MIEROOP, M. \\ 1992 Society and enterprise in Old Babylonian Ur \\ (Berliner Beiträge zum Vorderen Orient, 12). \\ Berlin: Dietrich Reimer Verlag. \\ VAN DER TOORN, $\mathrm{K}$. \\ 1994 From her cradle to her grave. The role of \\ religion in the life of the Israelite and the \\ Babylonian woman (Biblical Seminar Series, \\ 23). Sheffield: JSOT Press. \\ 1996a Family religion in Babylonia, Syria and \\ Israel. Continuity and change in the forms of \\ religious life. (Studies in the History and \\ Culture of the Ancient Near East, 7) Leiden: \\ E.J. Brill. \\ 1996b Domestic religion in ancient Mesopotamia. \\ K.R. Veenhof (Ed.) Houses and households in \\ ancient Mesopotamia (40 Rencontre \\ Assyriologique Internationale). Leiden, \\ Nederlands Historisch-Archaeologisch \\ Intstituut te Istanbul: 69-77. \\ 1999 Magic and the cradle: a reassessment. T. \\ Abusch; K. Van Der Toorn (Eds.) Mesopotamian
}

magic: textual, historical, and interpretative perspectives. (Ancient Magic and Divination, 1). Groningen, Styx Publications: 139-147. VEENHOF, K.R.

1982 A deed of manumission and adoption from the later old Assyrian period. G. van Driel; Th.J.H. Krispijn; M. Stol; K. R. Veenhof (Eds.) Zikir šumin. Assyriological studies presented to F.R. Kraus. Leiden, E.J. Brill: 359-385.

WESTBROOK, R.

1998 Legal aspects of care of elderly in the ancient Near East: conclusion. M. Stol; S.P. Vleeming (Eds.) The care of elderly in the ancient Near East (Studies in history and culture of the ancient Near East, 14). Leiden, E.J. Brill: 241-250.

WILSON, R.R.

1977 The form and the function of ancient Near Eastern genealogies. R.R. Wilson Genealogy and history in the biblical world. New Haven, Yale University Press: 56-136.

WOOLLEY, C.L.

1952 Carchemish III. The excavations in the inner town. London.

1976 The old Babylonian period. Ur excavations, Volume 7. London: British Museum Publications. 